\title{
Extracellular vesicles from regenerative human cardiac cells act as potent immune modulators by priming monocytes
}

\author{
Christien M. Beez ${ }^{1,2}$, Marion Haag ${ }^{1,3}$, Oliver Klein ${ }^{1,6}$, Sophie Van Linthout ${ }^{1,4,5}$, Michael Sittinger ${ }^{1,3}$
} and Martina Seifert ${ }^{1,2^{*}}$ (D)

\begin{abstract}
Background: Nano-sized vesicles, so called extracellular vesicles (EVs), from regenerative cardiac cells represent a promising new therapeutic approach to treat cardiovascular diseases. However, it is not yet sufficiently understood how cardiac-derived EVs facilitate their protective effects. Therefore, we investigated the immune modulating capabilities of EVs from human cardiac-derived adherent proliferating (CardAP) cells, which are a unique cell type with proven cardioprotective features.
\end{abstract}

Results: Differential centrifugation was used to isolate EVs from conditioned medium of unstimulated or cytokinestimulated (IFNY, TNFa, IL-1 $\beta$ ) CardAP cells. The derived EVs exhibited typical EV-enriched proteins, such as tetraspanins, and diameters mostly of exosomes $(<100 \mathrm{~nm})$. The cytokine stimulation caused CardAP cells to release smaller EVs with a lower integrin B1 surface expression, while the concentration between both CardAP-EV variants was unaffected. An exposure of either CardAP-EV variant to unstimulated human peripheral blood mononuclear cells (PBMCs) did not induce any $T$ cell proliferation, which indicates a general low immunogenicity. In order to evaluate immune modulating properties, PBMC cultures were stimulated with either Phytohemagglutin or anti-CD3. The treatment of those PBMC cultures with either CardAP-EV variant led to a significant reduction of T cell proliferation, pro-inflammatory cytokine release (IFNY, TNFa) and increased levels of active TGF $\beta$. Further investigations identified CD14 ${ }^{+}$cells as major recipient cell subset of CardAP-EVs. This interaction caused a significant lower surface expression of HLA-DR, CD86, and increased expression levels of CD206 and PD-L1. Additionally, EV-primed CD14 ${ }^{+}$cells released significantly more IL-1RA. Notably, CardAP-EVs failed to modulate anti-CD3 triggered T cell proliferation and pro-inflammatory cytokine release in monocultures of purified $\mathrm{CD}^{+} \mathrm{T}$ cells. Subsequently, the immunosuppressive feature of CardAPEVs was restored when anti-CD3 stimulated purified $\mathrm{CD}^{+}{ }^{+} \mathrm{T}$ cells were co-cultured with EV-primed $\mathrm{CD} 14^{+}$cells. Beside attenuated $T$ cell proliferation, those cultures also exhibited a significant increased proportion of regulatory $T$ cells.

Conclusions: CardAP-EVs have useful characteristics that could contribute to enhanced regeneration in damaged cardiac tissue by limiting unwanted inflammatory processes. It was shown that the priming of $\mathrm{CD} 14^{+}$immune cells by CardAP-EVs towards a regulatory type is an essential step to attenuate significantly T cell proliferation and proinflammatory cytokine release in vitro.

\footnotetext{
*Correspondence: martina.seifert@charite.de

${ }^{2}$ Institute of Medical Immunology, Charité-Universitätsmedizin Berlin,

Corporate Member of Freie Universität Berlin, Humboldt-Universität zu

Berlin, and Berlin Institute of Health, Campus Virchow Klinikum (CVK),

Foehrer Str. 15, 13353 Berlin, Germany

Full list of author information is available at the end of the article
} 
Keywords: Extracellular vesicles, Exosomes, Cardiac cells, Immunomodulation, CD14 ${ }^{+}$myeloid suppressive cells, Monocytes

\section{Background}

Cardiovascular diseases (CVD) are the leading cause of death worldwide [1] and deteriorate considerably the quality of many patient's life. To enhance prognosis and wellbeing of patients, a variety of cells were evaluated for their therapeutic potential in experimental and clinical studies, like cardiosphere-derived cells, cardiac progenitor cells, and mesenchymal stromal (MSC) cells from bone marrow, adipose tissue and other sources [2-8]. Another unique cardiac cell type are the human cardiacderived adherent proliferating (CardAP) cells, which are generated by outgrowth cultures of endomyocardial biopsies [9]. In a set of in vitro assays, it could be shown that CardAP cells are pro-angiogenic, anti-apoptotic and capable to modulate immune responses [10-12]. Furthermore, their administration improved significantly heart functions and impaired immune responses in vivo $[12,13]$. Beside these beneficial effects, CardAP cells also have additional advantages in comparison to other regenerative cell types. Firstly, the heart already primes CardAP cells. Histone modifications of cardiac-specific genes were shown to be different between murine cardiac-derived cells and murine bone marrow MSCs, which was correlated to an higher potential for cardiomyogenesis of cardiac than non-cardiac cells [14]. Secondly, Car$\mathrm{dAP}$ cells are predominantly negative for the membrane glycoprotein CD90 [9]. It was shown in a retrospective analysis of a clinical trial that the therapeutic benefit of applied cardiosphere-derived cells was negatively correlated to the expression of CD90 [15]. Thus, CardAP cells appear very useful for a therapeutic approach to treat CVD patients.

Initially, the observed beneficial effects of the different regenerative cell types were proposed to be facilitated by cell differentiation and integration into the damaged heart [16-18]. However, this mechanism could not be verified as studies failed to show a sufficient retention of therapeutically applied cells in the myocardium $[16,19]$. Instead, improved heart functions were induced in the absence of cells, when just their conditioned medium was applied in animal myocardial infarction models [20-22]. Subsequently, investigations focused on the released factors from regenerative cells.

Next to growth factors, cytokines and other proteins, nano-sized extracellular vesicles (EVs) were identified. These lipid bilayer structures can be discriminated in three subsets by their diameter and biogenesis. Apoptotic bodies $(>1 \mu \mathrm{m})$ and microvesicles $(1-.1 \mu \mathrm{m})$ are released by buddying from the cell membrane, whereas exosomes $(<.1 \mu \mathrm{m})$ originate from intracellularly located multivesicular bodies that fuse to the plasma membrane before they are released into the extracellular space. All three EV types act as potent intercellular communicators by delivering proteins, lipids, RNA and other molecules to a recipient cell [23-29]. Indeed, several studies showed that EVs derived from different cardiac cell types, like cardiomyocytes, endothelial cells, cardiac fibroblasts or cardiac progenitor cells, are able to mediate protective and regenerative effects in injured heart tissue [26, 28-32]. These studies mainly focused on the potential of cardiac-derived EVs to improve heart function by antifibrotic, anti-apoptotic, pro-angiogenic and proliferationinducing effects. All these observed beneficial effects contribute to the opinion that EVs are a very promising therapeutic tool and could eventually replace cellular therapies by application of allogeneic or autologous EVs to CVD patients. For an allogeneic approach, however, it would be necessary to evaluate their immunogenicity to guarantee their future safe usage in humans. Unfortunately, the interaction between the immune system and cardiac-derived EVs has rarely been studied. Furthermore, the ability to limit pro-inflammatory immune responses by immunomodulation can dramatically contribute to the therapeutic success, because lasting inflammation in the heart tissue has opposing effects on the regenerative process [33].

Data already available for EVs from regenerative noncardiac cells illustrate that these EVs are actually capable of combining low immunogenicity with immune modulating features. This includes in vitro observations like the suppression of induced $\mathrm{T}$ cell proliferation and cytokine release [34-37] as well as the induction of regulatory $\mathrm{T}$ cells $[37,38]$ by applied EVs from human or murine MSCs isolated from the bone marrow or umbilical cord. In a murine graft-versus-host-disease model, it could be demonstrated that human embryonic stem cell-derived MSC-EVs alleviated disease symptoms, which was attributed to an induced generation of regulatory $\mathrm{CD} 4^{+} \mathrm{T}$ cells by allogeneic antigen presenting cells [39].

Furthermore, it was shown that human bone marrowderived MSC-EVs were able to influence antigen presenting cells, like monocyte-derived macrophages in a lung injury model [40] or dendritic cells in vitro [41]. Additionally, it could be demonstrated that human adipose tissue-derived MSC-EVs preferably bind to human monocytes in vitro and induced the apoptosis of the 
pro-inflammatory $\mathrm{CD} 14^{+} \mathrm{CD} 16^{+}$subset, which led to their decreased proportion in the myeloid compartment [42].

To gain a better understanding regarding the effects and mechanisms of EVs from regenerative cardiac cells, we evaluated their impact on clinically relevant inflammatory immune responses by a set of in vitro assays. Therefore, we isolated EVs from the conditioned medium of cardioprotective CardAP cells cultured in the presence or absence of pro-inflammatory cytokines. This cytokine stimulation was applied to enhance anticipated immune modulating effects, since non-cardiac EVs were shown to profit from such a stimulation $[34,43]$. Also the immune modulating effects of CardAP cells were only observed in pro-inflammatory milieus [11-13].

Our in vitro results indicate that unstimulated as well as cytokine stimulated CardAP-EVs have a generally low immunogenicity and the therapeutic potential for enhancing cardiac tissue regeneration by limiting undesirable pro-inflammatory immune cell activation.

\section{Results}

CardAP cells release altered EVs upon cytokine stimulation CardAP-EVs were isolated by a stepwise centrifugation of the conditioned media (Fig. 1a), which was derived under either an unstimulated or a pro-inflammatory cytokine stimulation condition (INF $\gamma$, TNF $\alpha$, IL-1 $\beta$ ). Indeed, CardAP cells express receptors for the three cytokines and the culturing with cytokines for $20 \mathrm{~h}$ statistically enhanced the expression of immunologically relevant markers on the surface of CardAP cells, such as vascular cell adhesion protein-1 (CD106), programmed death ligand 1 and 2 (PD-L1/2) and intercellular adhesion molecule-1 (CD54), while their spindle-shaped morphology and typical mesenchymal markers were unaffected (Additional file 1: Figure S1).

Neither the EV protein amount released by $1 \times 10^{6}$ CardAP cells as determined by BCA assay (Fig. 1b) nor the particle concentration of EVs released by $1 \times 10^{6}$ CardAP cells as determined by NTA (Fig. 1c) was influenced by the cytokine stimulation. Both CardAP-EV variants exhibited also typical sphere-like shapes in sizes ranging from 21 to $295 \mathrm{~nm}$ as observed by TEM (Fig. 1d). Quantitative analysis of the determined diameters demonstrated an asymmetrical distribution (Fig. 1e), while most vesicles from both variants (at least $82 \%$ ) were smaller than $100 \mathrm{~nm}$. Unstimulated EVs (median $=73.80 \mathrm{~nm}$ ) appeared to be larger in their median diameter in comparison to cytokine stimulated EVs (median $=67.14 \mathrm{~nm}$ ), (Fig. 1e). This difference between the median diameters of both CardAP-EV variants was further verified by NTA (Additional file 1: Figure S2). Typical EV markers, like Ecto-5'-nucleotidase (CD73), integrin $ß 1$ (CD29) and the tetraspanins CD9, CD81 and CD63, were detected on isolated CardAP-EVs by flow cytometry (Fig. 1f). Unstimulated CardAP-EVs showed a statistically enriched level of CD29 in comparison to cytokine stimulated EVs. Immunological markers, such as HLA-ABC, HLA-DR, CD106 and PD-L1, were not or at very low levels detectable (Fig. 1f).

CD73 and CD29 were also detected on both CardAPEV variants from three different CardAP donors by a liquid chromatograph/electron spray ionisation mass spectrometry (LC/ESI-MS) approach. In total 186 proteins were identified and their interaction as well as functional enrichment in biological processes or cellular compartment was analysed by using String Network Database (Fig. 2a, Additional file 1: Table S1). Generally, most proteins $(156 / 186)$ could be assigned to the extracellular exosome compartment, like heat shock proteins, integrins or enzymes (e.g. GAPDH). Additionally, CardAP-EVs exhibited proteins that are involved in biological processes, such as angiogenesis (e.g. heparan sulfate proteoglycan 2, neuropillin), wound healing (endoglin, annexin5) or immune system processes (annexin 1, galectin 1). Comparative analysis of the determined exponentially modified protein abundance index (emPAI) between all three CardAP donors reveals that several proteins were identified in all samples, like CD73, while others seem to be donor-specific (Fig. 2b). Furthermore, proteins were exclusively identified for cytokine stimulated EVs, such as TNFo inducible protein and dipeptidyl

\footnotetext{
(See figure on next page.)

Fig. 1 Inflammatory cues change the phenotype of CardAP-EVs. a The differential ultracentrifugation protocol is shown to isolate EVs from the conditioned medium under unstimulated (EVs) or cytokine stimulated conditions (EVs $\left.s^{(\mathrm{cyt})}\right)$. b EV protein amount released from $1 \times 10^{6} \mathrm{CardAP}$ cells is presented as median with interquartile range $\left(n=10-21\right.$; six different CardAP donors). c Particle concentration of EVs released by $1 \times 10^{6}$ CardAP cells is presented as median with interquartile range ( $n=6$; three different CardAP donors). $\mathbf{d}$ Representative transmission electron microscopy (TEM) images (upper row) with an enlarged region (white square) of interest (lower row) are displayed for both EV variants; scale bars represent $200 \mathrm{~nm}$. e The diameter distribution as observed by TEM is shown for both EV variants of one CardAP donor. f Flow cytometric analyses are presented as median with interquartile range of normalized geometrical mean fluorescence intensities (normalized MFI calculated as ratio of stained to unstained) for tetraspanins (CD9, CD81, CD63), immunological relevant markers (CD54, PD-L1, CD106, HLA-ABC, HLA-DR) and mesenchymal markers (CD29, CD73, CD44, CD90) $\left(n=5-16\right.$; at least three different CardAP donors). Mann-Whitney U-test; ${ }^{* * *} p<.001,{ }^{* *} p<.01$, ${ }^{*} \mathrm{p}<.05$
} 


\section{a}

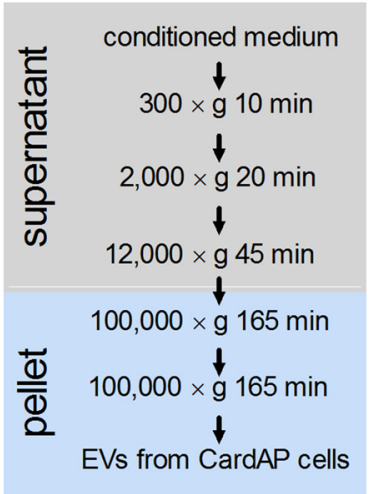

b

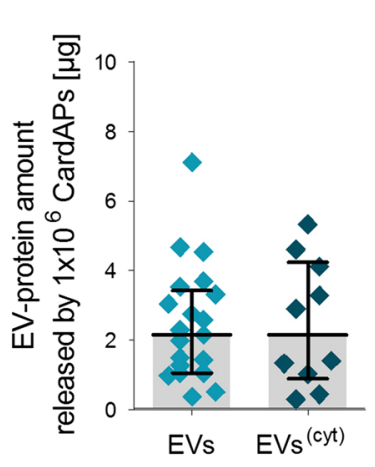

C

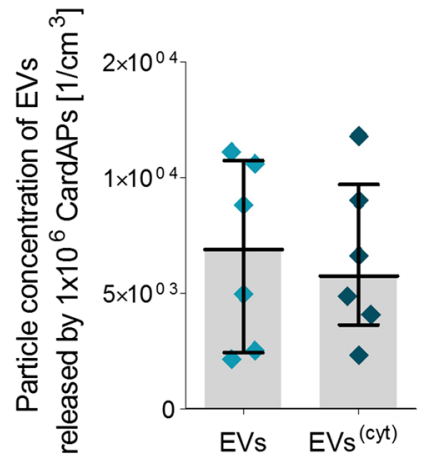

d

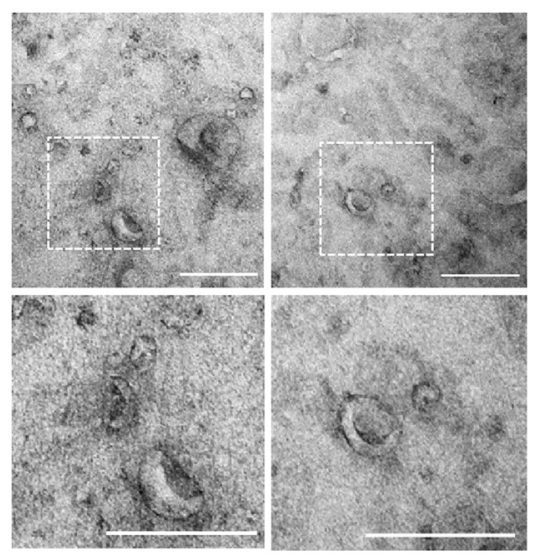

f 300

$250-$

150

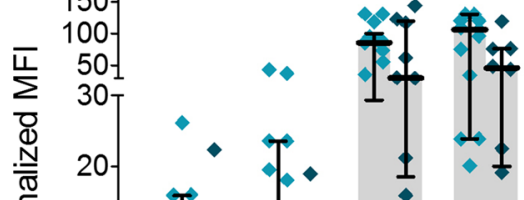

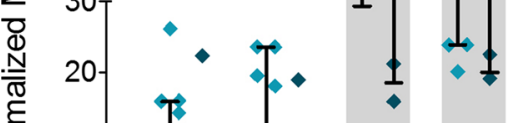

e

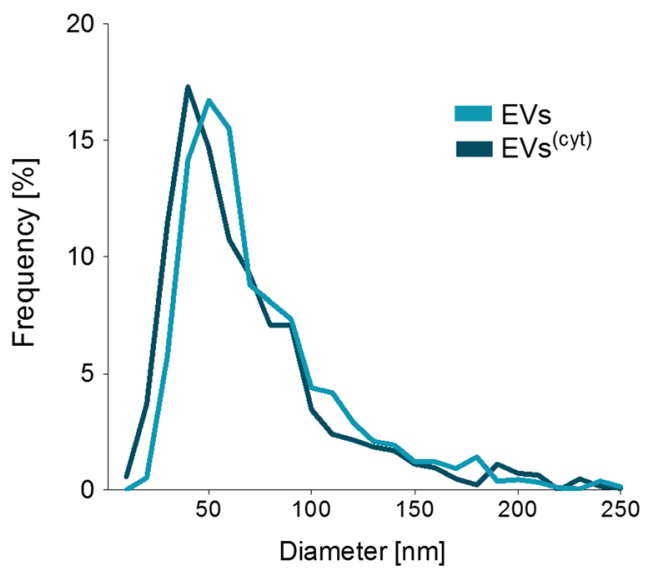

은

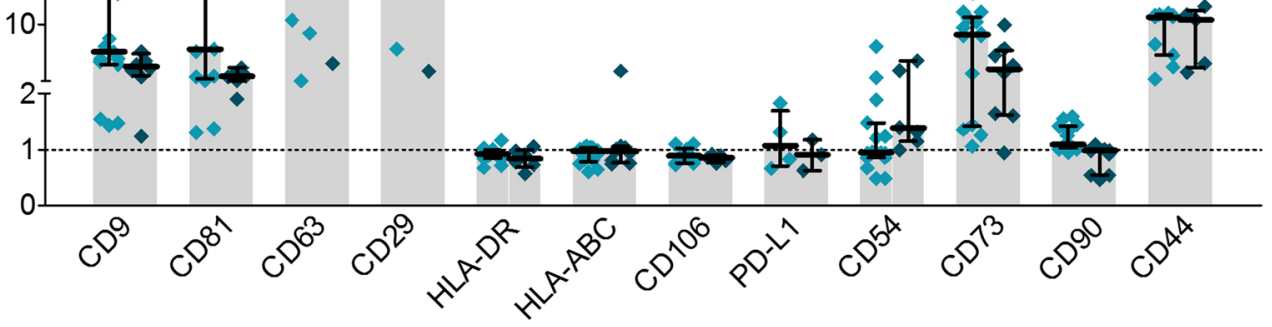



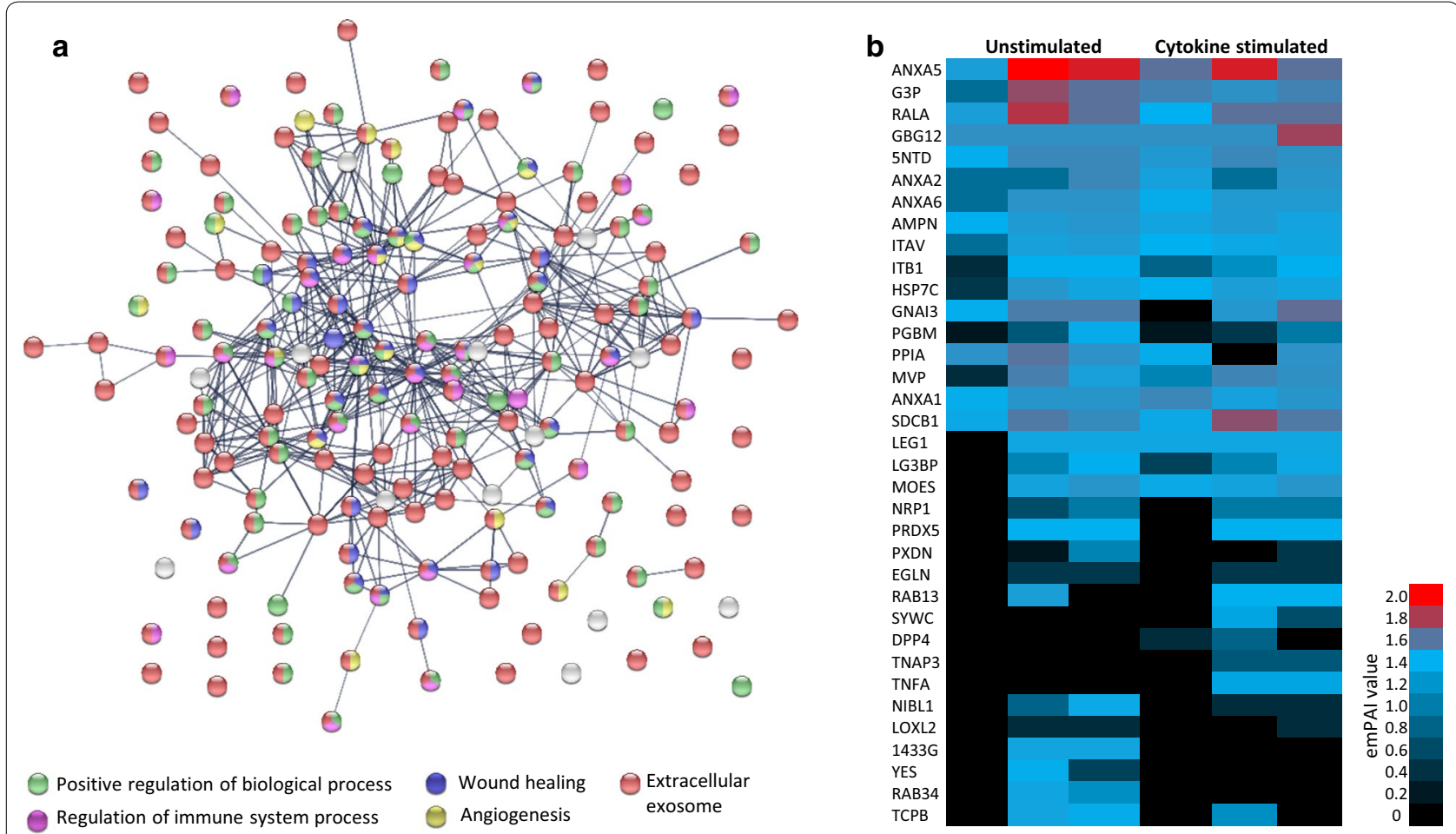

Fig. 2 The inflammatory cue changes slightly the proteome of CardAP-EVs. Peptides were derived from unstimulated EVs (unstimulated) and cytokine stimulated EVs (cytokine stimulated) by an overnight digestion with trypsin. By liquid chromatography/electron spray ionization mass spectrometry (LC/ES MS) obtained mass spectra were evaluated by MASCOT software searching for protein matches in the SwissProt 51.9 database. a The interaction of proteins was visualized with the help of String database. Protein interactions were shown as connecting lines and were categorized as known interactions (grey connecting lines). The detected proteins are shown as nodes, which appear coloured due to their biological process or localisation (extracellular exosome $=$ red, positive regulation of cellular process $=$ green, angiogenesis $=$ yellow, wound healing = blue, regulation of immune system process= magenta). $\mathbf{b}$ Shown is a heat map of the exponentially modified protein abundance index (emPAI) for 35 selected proteins from in total 186 detected proteins and for both EV variants from three CardAP donors. Not detected proteins corresponds to an emPAl value of 0

peptidase 4, or on unstimulated EVs, like Ras-related protein Rab-34 or tyrosine-protein kinase Yes (Fig. 2b).

\section{CardAP-EVs attenuate pro-inflammatory immune responses in PBMC cultures}

In vitro immune assays are an important initial tool to evaluate future therapies for their immunogenicity and immune modulating capabilities $[44,45]$. For that purpose, we isolated human PBMCs from healthy donors and treated them with one of either EV variant, PBS or they were left untreated in the absence or presence of different $T$ cell stimuli (Fig. 3a).

Both CardAP-EV variants exhibited a generally low immunogenicity, as a 5-day exposure of unstimulated PBMCs to each EV variant did not induce any $\mathrm{T}$ cell proliferation (Additional file 1: Figure S3). On the other hand, the treatment with either CardAP-EV variant significantly reduced the $\mathrm{CD} 4^{+}$and $\mathrm{CD} 8^{+} \mathrm{T}$ cell proliferation in PBMC cultures stimulated with either Phytohemagglutin
(PHA) (Fig. 3b, c) or anti-CD3 (Fig. 3d, e) in comparison to the respective PBS control. Interestingly, the $\mathrm{CD}_{4}^{+}$and $\mathrm{CD}^{+} \mathrm{T}$ cell proliferation was even greater diminished in PHA stimulated PBMC cultures treated with cytokine stimulated CardAP-EVs (median $.85 \mathrm{CD}^{+}$; median .94 $\mathrm{CD}^{+}$) than with unstimulated CardAP-EVs (median .90 $\mathrm{CD}^{+}$, median $.96 \mathrm{CD}^{+}$). A similar trend was detcted in anti-CD3 stimulated PBMCs. The treatment with either EV variant also contributed towards a less pro-inflammatory cytokine profile under PHA stimulation (Fig. 4a) or anti-CD3 stimulation (Fig. 4b), as observed by significant lower IFN $\gamma$ as well as TNF $\alpha$ levels and a higher level of active TGF $\beta$. The IL-17a release in PHA stimulated PBMCs and IL- $1 ß$ in anti-CD3 stimulated PBMCs were reduced by trend upon CardAP-EV treatment (Additional file 1: Figure S4). Additionally, IL-10 was increased in PBMC cultures treated with cytokine stimulated CardAP-EVs by trend under PHA stimulation (Fig. 4a) and statistically significant under anti-CD3 stimulation (Fig. 4b) in comparison to the respective PBS controls. 


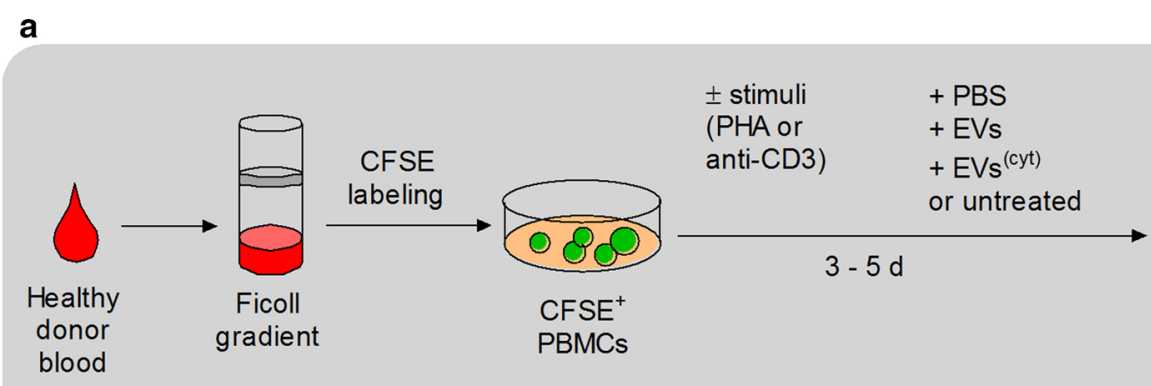

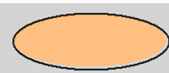

Analysis of cytokines by ELISA and Multiplex Assay

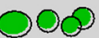

Analysis of proliferation \& composition by FACS b
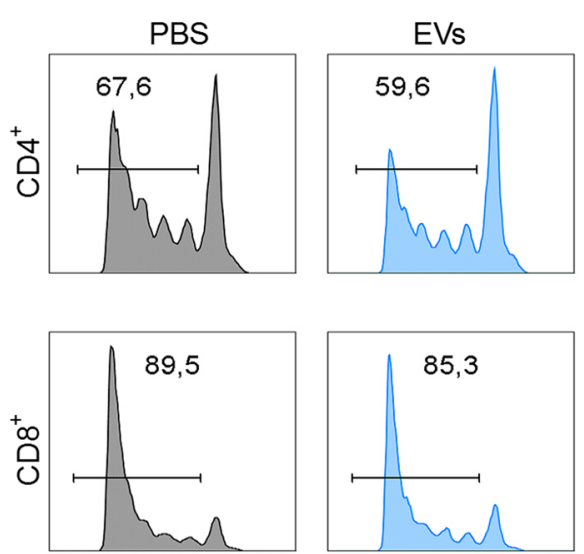

$x=$ CFSE, $y=\%$ of Max

PBMCs + PHA

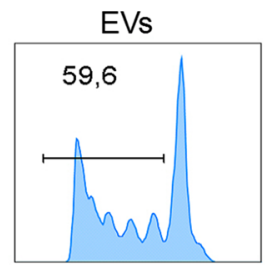

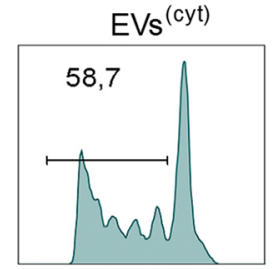

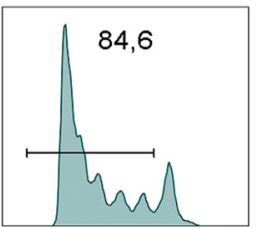

d
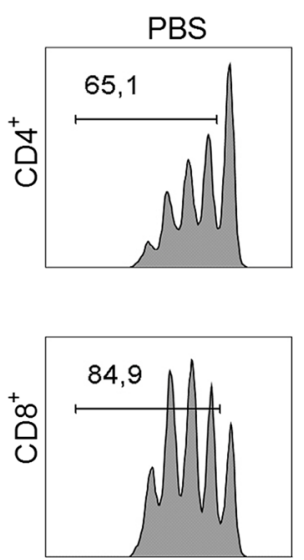

$x=$ CFSE, $y=\%$ of Max

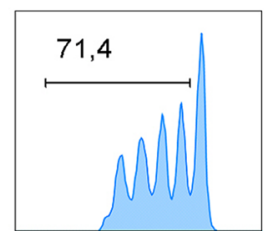

PBMCs + anti-CD3
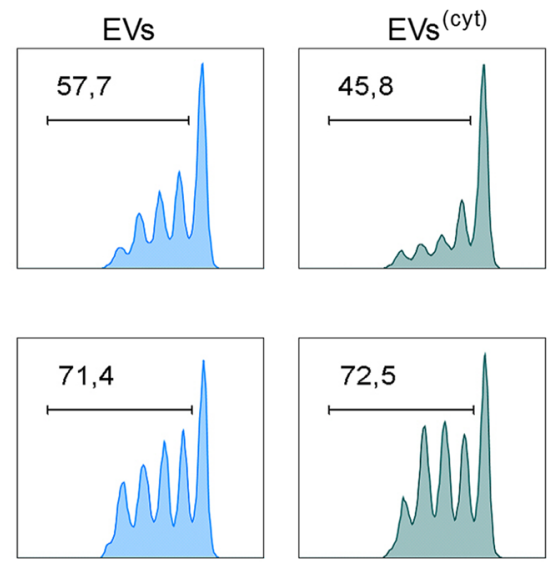

c

PBMCs + PHA
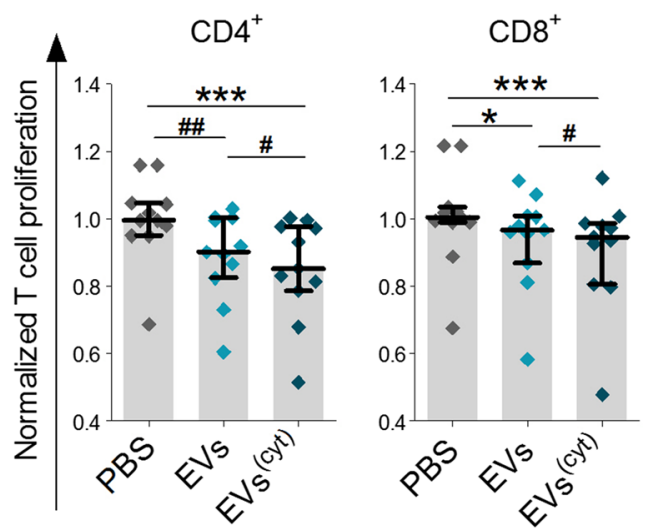

Fig. 3 CardAP-EVs diminish PHA and anti-CD3 induced T cell proliferation in PBMC cultures. $3 \times 10^{5}$ CFSE-labelled PBMCs were stimulated with PHA or anti-CD3, treated with either unstimulated (EVs) or cytokine stimulated (EVs ${ }^{(\mathrm{cyt})}$ ) EVs, PBS in equal volume of the EVs (PBS) or left untreated and analysed after 3-5 days by flow cytometry. T cell proliferation frequencies were normalized to the untreated control. a The general immune assay design is shown. $\mathbf{b}, \mathbf{d}$ Representative flow cytometric plots display the frequencies of proliferated $\mathrm{CD}^{+}$and $\mathrm{CD} 8^{+} \mathrm{T}$ cells in PHA stimulated PBMCs (b) or in in anti-CD3 stimulated PBMCs (d). The normalized proliferation of CD4 ${ }^{+}$(left) and CD8 ${ }^{+}$(right) T cells in PHA stimulated PBMCs (c) or in anti-CD3 stimulated PBMCs (e) is presented for the treatment with either CardAP-EV variant and PBS as median with interquartile range (PHA $n=11$; four different CardAP donors; five different PBMC donors) (anti-CD3 $n=9$; four different CardAP donors; five different PBMC donors). Friedman Test with Dunn's multiple comparison test: ${ }^{* *} p<.001,{ }^{* *} p<.01,{ }^{*} p<.05$ or Wilcoxon matched-pairs signed rank test; ${ }^{\# \#} p<.001,{ }^{\# \#} p<.01$, $p<.05$ 


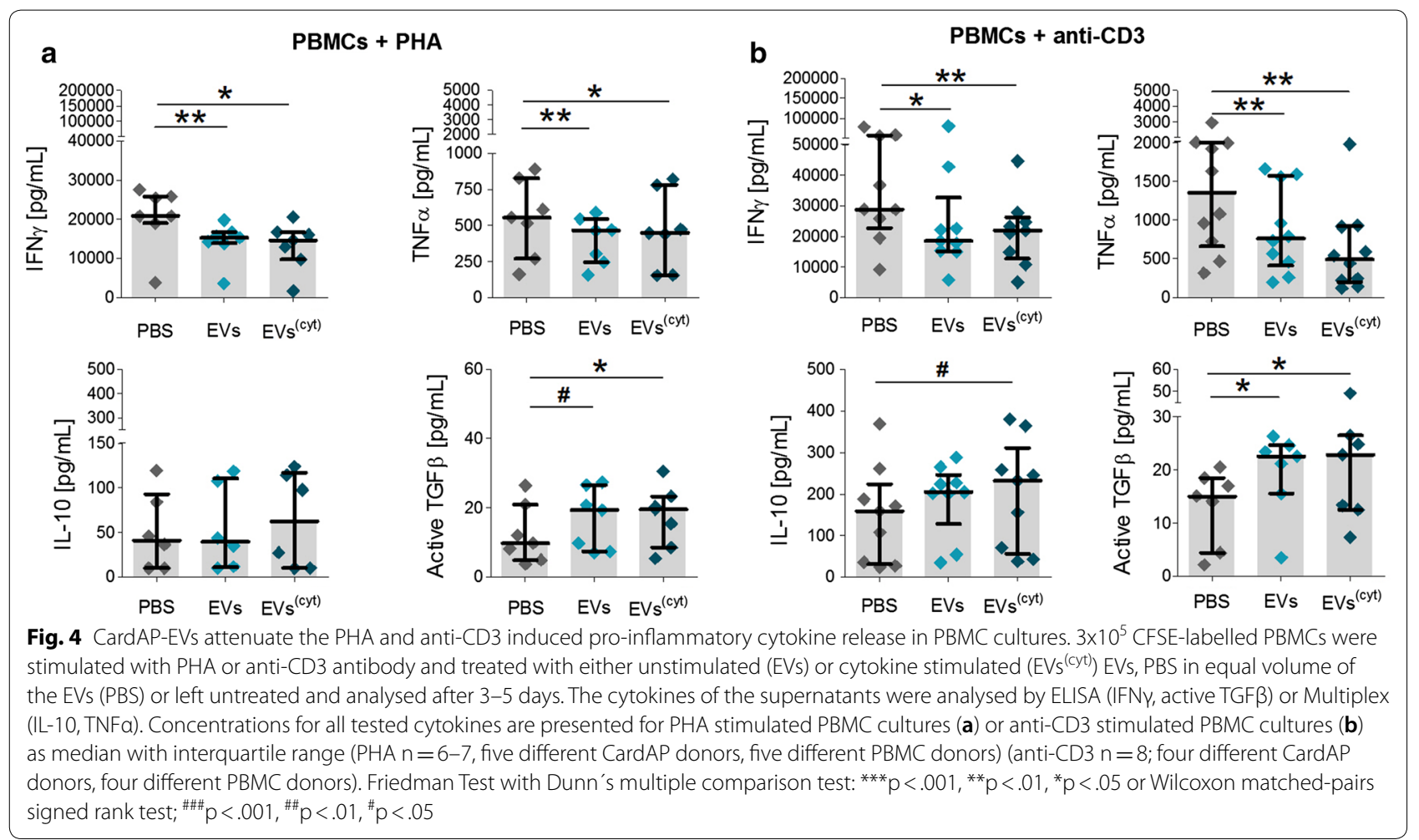

\section{CardAP-EVs primarily target $\mathrm{CD} 14^{+}$cells and induce a regulatory phenotype}

To unravel the recipient cell of CardAP-EVs, total PBMC cultures were treated with fluorescently labelled CardAP-EVs (DiD ${ }^{+}$EVs) for $24 \mathrm{~h}$. Flow cytometric analysis clearly illustrated that $\mathrm{DiD}^{+} \mathrm{EVs}$ were primarily interacting with $\mathrm{CD}_{14}{ }^{+}$cells $\left(96.6 \% \mathrm{DiD}^{+}\right.$cells) rather than with CD14 ${ }^{-}$immune cells (2.8\% $\mathrm{DiD}^{+}$cells) (Fig. 5b), which we could also verify by the co-localization of both signals (Fig. 5a). After 3 days, the frequency of $\mathrm{CD} 14^{+}$cells was significantly increased in unstimulated PBMC cultures treated with either CardAP-EV variant (Fig. 5c) respectively to the PBS controls. Furthermore, the phenotype of EV-primed CD14 ${ }^{+}$cells changed dramatically. Both CardAP-EV variants (Fig. 5d) raised significantly the surface expression levels of PD-L1 and significantly lowered the expression levels of HLA-DR and CD86 in comparison to the PBS controls. Also CardAP-EVs significantly enhanced the surface expression levels of the macrophage mannose receptor 1 (CD206). Notably, the expression of PD-L1 was significantly more enhanced by cytokine stimulated CardAP-EVs in comparison to the unstimulated counterpart.

\section{EV-primed $\mathrm{CD} 14^{+}$cells are necessary to suppress immune responses}

The question arouse whether EV-primed CD14 ${ }^{+}$cells are playing a role in the previously described immune suppressive effects in PBMC cultures. Therefore, we adjusted the assay by using purified $\mathrm{CD}^{+} \mathrm{T}$ cells and $\mathrm{CD} 14^{+}$monocytes, generated by MACS sorting, instead of PBMCs. The purified $\mathrm{CD}^{+} \mathrm{T}$ cells were stimulated with anti-CD3 for 3 days and either cultured with EVprimed $\mathrm{CD}_{14}{ }^{+}$cells or treated with CardAP-EV corresponding controls (Fig. 6a). Anti-CD3 induced CD4 ${ }^{+}$or $\mathrm{CD}^{+} \mathrm{T}$ cell proliferation was not affected in isolated $\mathrm{CD}^{+} \mathrm{T}$ cell cultures treated with either CardAP-EV variant in respect to the PBS-control (Fig. 6b). In contrast, combination of purified $\mathrm{CD}^{+} \mathrm{T}$ cells with $\mathrm{EV}$ primed $\mathrm{CD} 14^{+}$cells resulted in a significant reduction of $\mathrm{CD}^{+}$as well as $\mathrm{CD}^{+} \mathrm{T}$ cell proliferation (Fig. 6c). Likewise, no changes in the amount of released IFNy or TNF $\alpha$ were detected in the purified $\mathrm{CD}^{+} \mathrm{T}$ cells culture setting (Fig. 7a), while significant lower levels of pro-inflammatory IFN $\gamma$ were detected in co-cultures of $\mathrm{CD}^{+} \mathrm{T}$ cells with EV-primed CD14 ${ }^{+}$cells (Fig. 7b). 

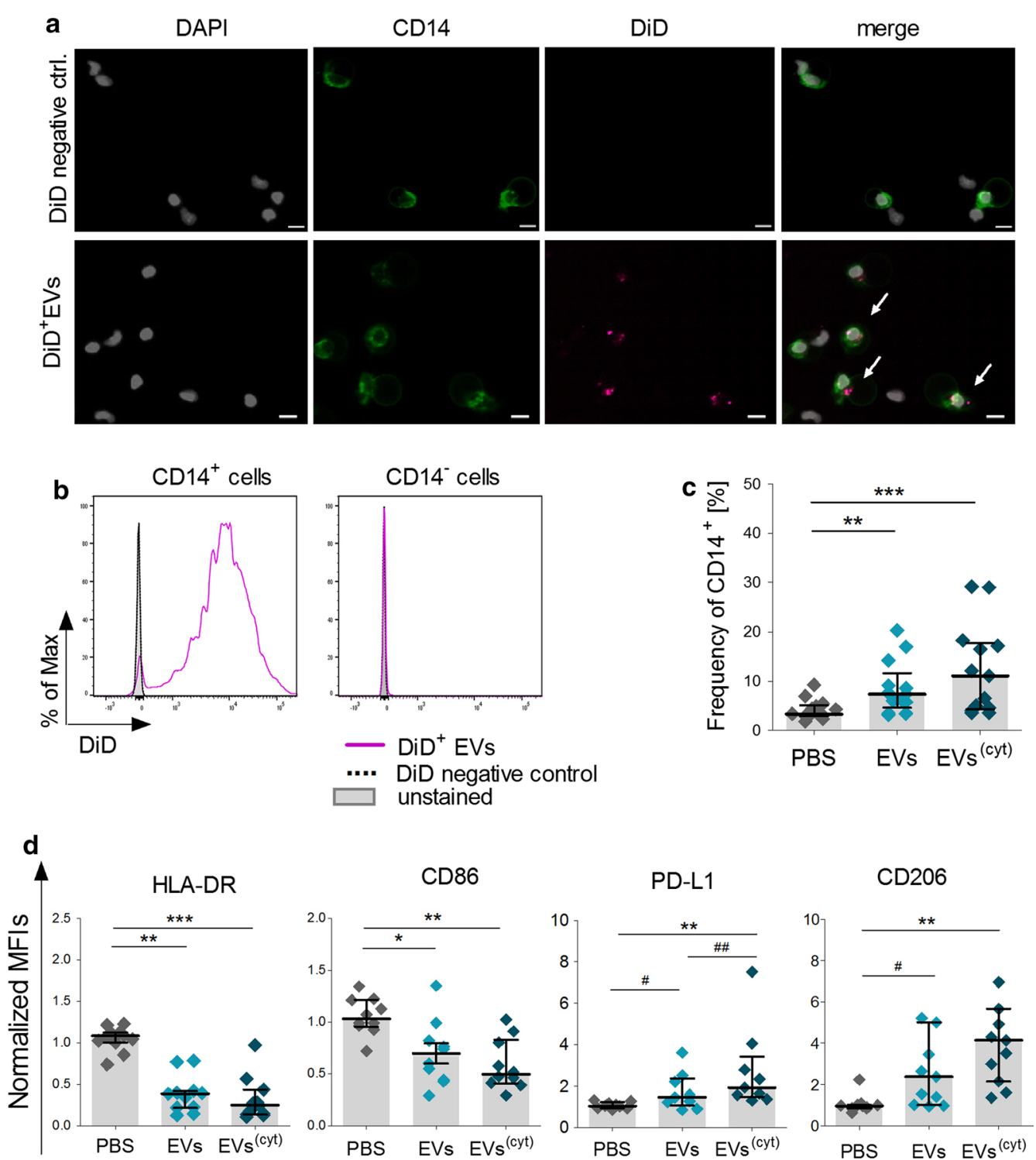

Fig. 5 CardAP-EVs prime CD $14^{+}$monocytes in unstimulated PBMC cultures towards a regulatory $\mathrm{CD} 14^{+}$myeloid cell type. $1 \times 10^{6} \mathrm{PBMCs}$ were treated with DiD-labelled CardAP-EVs for $24 \mathrm{~h}$ and analysed by microscopy or flow cytometry. a Representative images are illustrating co-localization (white arrows) of DiD ${ }^{+}$EVs (magenta) with CD14+ PBMCs (green) in total PBMCs (pseudo coloured white for DAPI) $(n=2$; three different CardAP donors, two different PBMC donors). Scale bars represent $10 \mu \mathrm{m}$. b Representative histograms of the flow cytometric analysis are shown for $\mathrm{CD}_{14}{ }^{+}$and $\mathrm{CD} 14^{-}$immune cells $\left(\mathrm{n}=2\right.$; three CardAP donors; two different PBMC donors). For the phenotypical analysis, $1 \times 10^{6} \mathrm{PBMCs}$ were treated with unstimulated (EVs) or cytokine stimulated EVs (EVs $\left.s^{(\mathrm{cyt})}\right)$, PBS in equal volume of the EVs (PBS) or left untreated. After 3 days, cells were analysed by flow cytometry. $\mathbf{c}$ Frequencies of CD14 $4^{+}$cells in PBMCs are presented for cultures treated with PBS, EVs or EVs ${ }^{(\mathrm{cyt})}$. $\mathbf{d}$ Flow cytometric surface expression data are presented as median with interquartile range of normalized geometrical mean fluorescence intensities (normalized MFI calculated as ratio of stained to unstained) for the immunological markers HLA-DR, CD86, PD-L1 and CD206 ( $n=11$; four CardAP donors, four PBMC donors). Friedman Test with Dunn's multiple comparison test: ${ }^{* * *} \mathrm{p}<.001,{ }^{* *} \mathrm{p}<.01,{ }^{*} \mathrm{p}<.05$ or Wilcoxon matched-pairs signed rank test; $\# \#$ $<$.001, \#\# $\mathrm{p}<.01, \# \mathrm{p}<.05$

TNF $\alpha$ was significantly reduced by $\mathrm{CD} 14^{+}$cells primed by cytokine stimulated CardAP-EVs and a similar effect is visible by trend for $\mathrm{CD} 14^{+}$cells treated with unstimulated CardAP EVs prior to the co-culture with T cells (Fig. 7b). Interestingly, the IL-10 level was found to be significantly reduced in co-cultures with $\mathrm{CD} 14^{+}$cells that were primed by cytokine stimulated CardAP-EVs, whereas active TGFß was detectable on very low levels (Fig. 7b). Nevertheless, the frequency of regulatory $\mathrm{T}$ cells $\left(\mathrm{CD} 4{ }^{+} \mathrm{CD} 127^{-} \mathrm{CD} 25^{+} \mathrm{Foxp} 3^{+}\right)$was significantly 


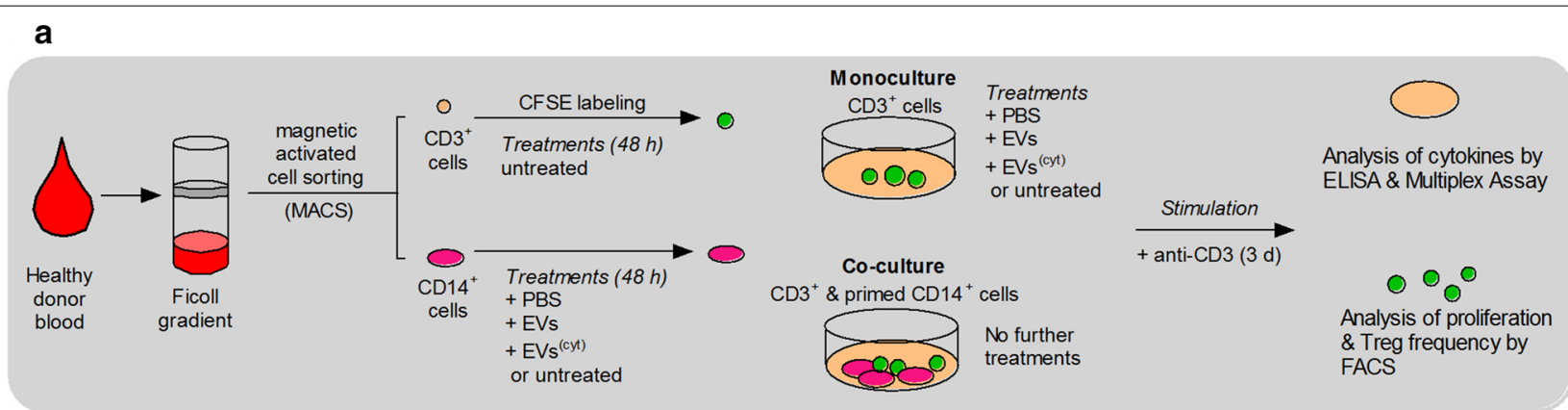

b

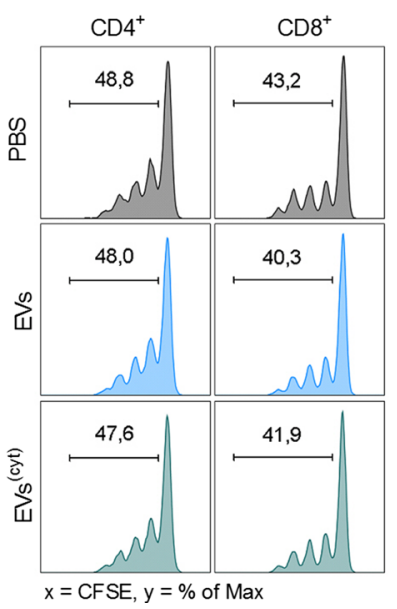

$\mathrm{CD} 4^{+}$

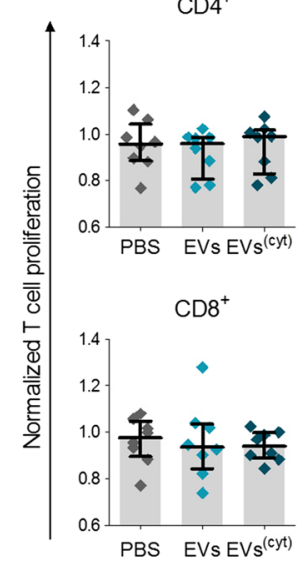

c

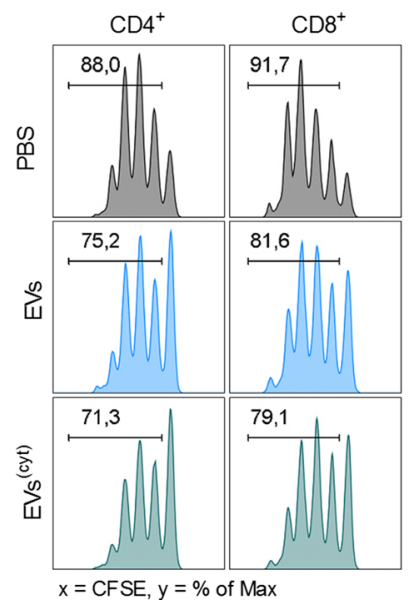

Co-culture $\mathrm{CD}^{+} \&$ primed $\mathrm{CD} 14^{+}$cells + anti-CD3

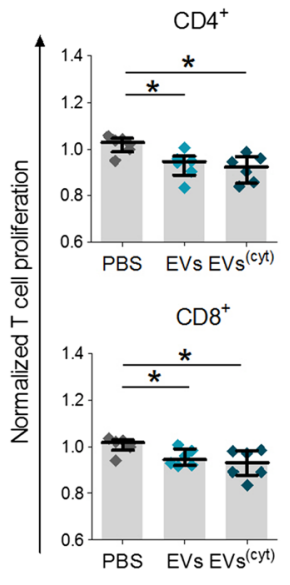

Fig. 6 CardAP-EVs diminish anti-CD3 induced T cell proliferation only in the presence of CD14 ${ }^{+}$cells. CD3 ${ }^{+}$and $C D 14^{+}$cells were isolated by MACS and cultured unstimulated for $48 \mathrm{~h}$. Here, $C D 14^{+}$cells were additionally treated with either unstimulated (EVs) or cytokine stimulated (EVs $\left.{ }^{(\mathrm{Cyt})}\right) \mathrm{EV}_{\mathrm{s}}$, PBS in equal volume of the EVs (PBS) or left untreated. Afterwards, CD14 ${ }^{+}$cells were co-cultured 1:5 with CD3 ${ }^{+}$cells and stimulated with anti-CD3. Additionally, a negative control was incorporated by treating anti-CD3 stimulated $\mathrm{CD}^{+}$cells with either CardAP-EV variant, PBS or left untreated. After 3 days, the cells were harvested and analysed by flow cytometry. T cell proliferation frequencies were normalized to the untreated control. a The general immune assay design is shown. Representative flow cytometric plots display the frequencies of proliferated CD4 $4^{+}$and $\mathrm{CD} 8^{+} \mathrm{T}$ cells in anti-CD3 stimulated monocultures of $\mathrm{CD} 3^{+}$cells ( $\mathbf{b}$, left) and anti-CD3 stimulated co-cultures of $\mathrm{CD} 3^{+}$cells with primed $\mathrm{CD} 14^{+}$cells (c, left). The normalized proliferation of $\mathrm{CD} 4^{+}$(upper graph) and $\mathrm{CD} 8^{+}$(lower graph) T cells in anti-CD3 stimulated monocultures of $\mathrm{CD} 3^{+}$cells $(\mathbf{b}$, right) or in co-culture with primed CD14 ${ }^{+}$cells (c, right) is presented for the treatment with either CardAP-EV variant and PBS as median with interquartile range (monocultures $n=7$; four different CardAP donors; five different PBMC donors) (co-cultures $n=5$; four different CardAP donors; four different PBMC donors). Friedman Test with Dunn's multiple comparison test: ${ }^{* *} p<.001,{ }^{* *} p<.01,{ }^{*} p<.05$ or Wilcoxon matched-pairs signed rank test; $\# \#$ p $<.001, \# \mathrm{p}<.01, \# \mathrm{p}<.05$

enhanced in those co-cultures with EV-primed CD14 $4^{+}$ cells in comparison to the control setting of PBStreated $\mathrm{CD}_{14}{ }^{+}$cells (Fig. 8a, b). Analysis of supernatants from $48 \mathrm{~h}$ primed $\mathrm{CD} 14^{+}$cells showed that interleukin 1 receptor antagonist (IL-1RA) has been significantly enhanced (Fig. 8c), while IL-1 $\beta$, IFN $\gamma$ and IL-10 were not detectable in those supernatants (data not shown).

\section{Discussion}

Cardiac-derived cells, like CardAP cells, demonstrated a great potential to treat CVD by pro-angiogenic, antifibrotic, anti-apoptotic and immune modulating features
[9-13, 46-48]. Over the last years, evidence accumulated that paracrine modulators, especially extracellular vesicles, are key players of those regenerative effects [28, 49 , 50]. There is, however, just very few information available whether cardiac-derived EVs are able to liberate regenerative processes by limiting chronic inflammation in the cardiac tissue. Therefore, we investigated the capacity of unstimulated or pro-inflammatory stimulated CardAPEVs to modulate crucial immune responses in vitro.

We could show for the first time to our knowledge that cardiac-derived EVs are potent modulators of CD14 ${ }^{+}$ monocytes by shifting their surface marker profile towards a rather immune regulatory one and that solely 


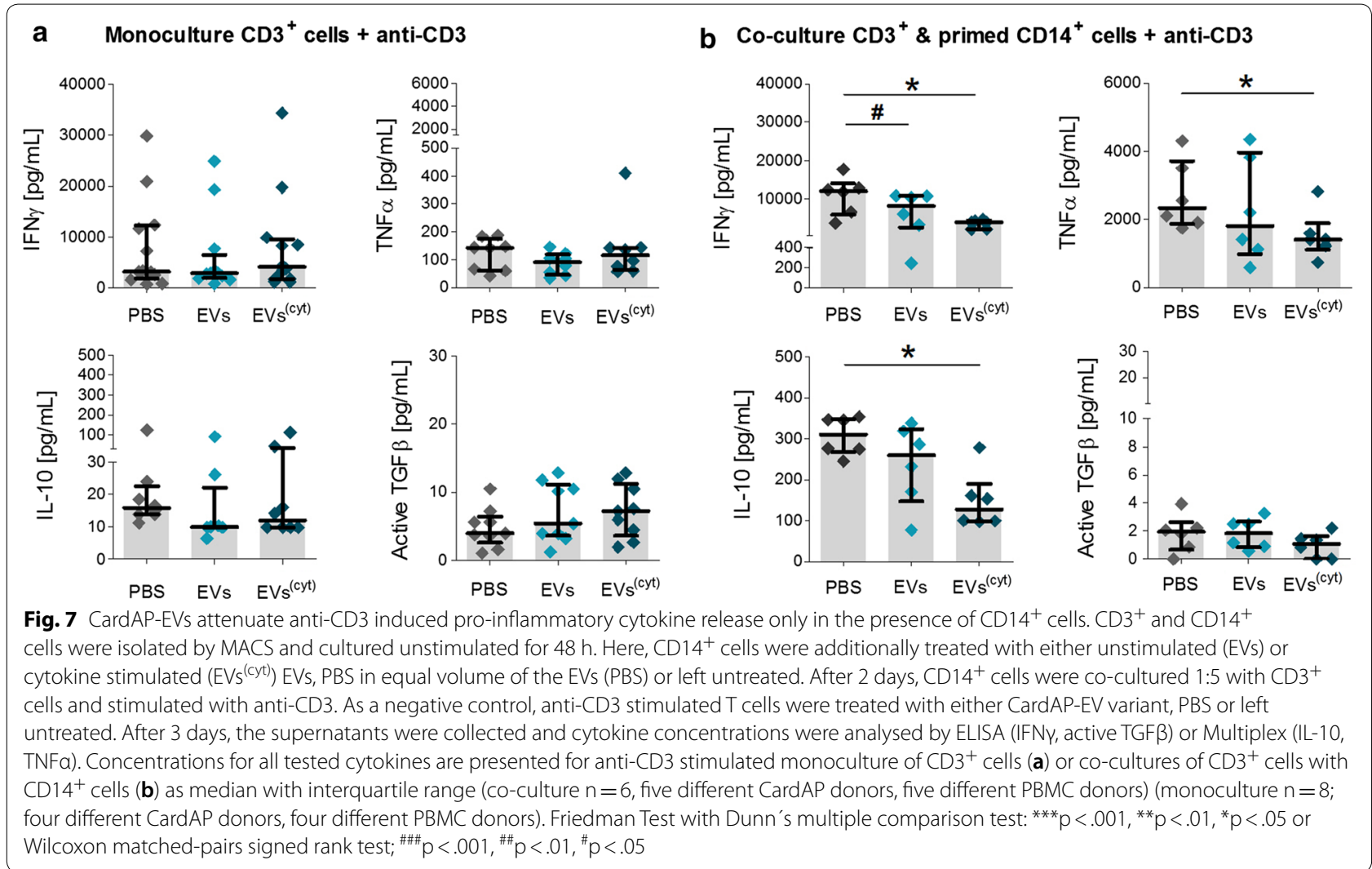

the presence of EV-primed $\mathrm{CD} 14^{+}$cells is capable to attenuate adaptive $\mathrm{T}$ cell immune responses.

Both CardAP-EV variants demonstrated typical EV characteristics and a low immunogenic phenotype. The protein amount as well as the particle concentration of EVs released by $1 \times 10^{6}$ CardAP cells was comparable between both conditions. But their size and marker expression differed significantly. The majority of CardAP-EVs exhibited dominantly diameter measures of exosomes, while cytokine stimulated EVs showed a smaller median diameter. This observation has not been described yet and might be influenced by an altered composition of exosomes. Exosomes have been described to be a heterogeneous EV population, including their size and transported proteins [23, 51]. It is further corroborated by a significant lower CD29 detection on cytokine stimulated EVs as observed by flow cytometry. Furthermore, other proteins were exclusively detected under either cytokine stimulated condition (e.g. TNF $\alpha$ induced protein 3) or unstimulated condition (e.g. Ras-related protein Rab-34) by LC/ ESI-MS. This observation has to be validated by analysing a greater number of CardAP donors. The majority of identified proteins $(156 / 186)$ could be assigned to the extracellular exosome compartment, which also included surface markers already detected by flow cytometry. These typical EV-enriched proteins, such as CD73, were detectable in comparable expression levels on both CardAP-EV variants. A low immunogenicity would be ensured by a very low HLA-ABC expression and the complete absence of HLA-DR, which both were not detectable by LC/EMI-MS. Indeed, this could be verified by an absence of any $\mathrm{T}$ cell proliferation response against the applied CardAP-EVs in PBMC cultures. This is in accordance with recent studies, where any $\mathrm{T}$ cell proliferation was induced by human embryonic stem cell-derived MSC-EVs in mouse spleenocyte cultures [52] or by EVs from amniotic fluid stem cells in human PBMC cultures [53]. Importantly, we found that EVs interacted pre-dominantly with $\mathrm{CD} 14^{+}$cells in those PBMC cultures. So far, evidence is missing whether CardAP-EVs have been internalized. But we would argue that EVs are rather taken up by $\mathrm{CD} 14^{+}$ cells due to their enhanced phagocytosis capability. Likewise, others described a preferred interaction of $\mathrm{CD}_{14}{ }^{+}$cells with vesicles released by labelled human MSCs derived from the bone marrow in a trans-well culture system [43].

We found that CardAP-EVs treatment changed $\mathrm{CD}_{1}{ }^{+}$cells towards a regulatory phenotype by 


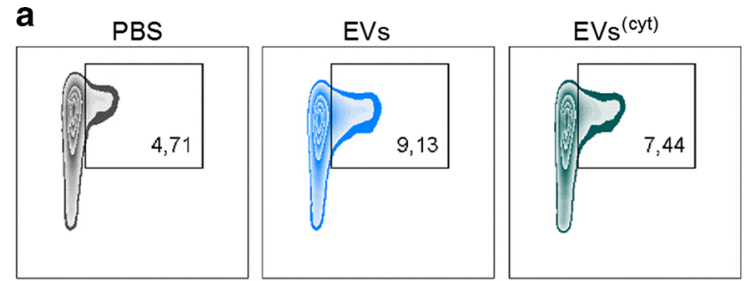

$\mathrm{x}=$ Foxp3, $\mathrm{y}=\mathrm{CD} 25$
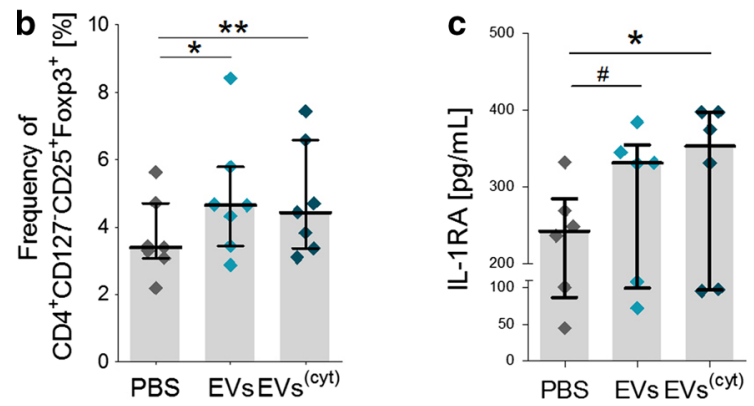

Fig. 8 CardAP-EVs increase the frequency of regulatory $T$ cells in anti-CD3 induced co-cultures of $\mathrm{CD}^{+}$cells with primed $\mathrm{CD}_{14}{ }^{+}$ cells. $\mathrm{CD}^{+}$and $\mathrm{CD}_{14}{ }^{+}$cells were isolated by MACS and cultured unstimulated for $48 \mathrm{~h}$. Here, CD14 ${ }^{+}$cells were additionally treated with either unstimulated (EVs) or cytokine stimulated (EVs $\left.s^{(\mathrm{Cyt})}\right)$ EVs, PBS in equal volume of the EVs (PBS) or left untreated. Afterwards, $\mathrm{CD} 14^{+}$cells were co-cultured 1:5 with $\mathrm{CD}^{+}$cells and stimulated with anti-CD3. After 3 days, the cells were harvested and analysed by flow cytometry. a Representative flow cytometric plots (Foxp3 vs CD25) display the frequencies of regulatory T cells $\left(\mathrm{CD}^{+}{ }^{+} \mathrm{CD} 197^{-} \mathrm{CD} 25^{+} \mathrm{Foxp}^{+}\right)$in anti-CD3 stimulated co-cultures of $\mathrm{CD}^{+}$cells and $\mathrm{CD} 14^{+}$cells primed with PBS (left), EVs (middle) and $\mathrm{EVS}^{(\mathrm{cyt})}$ (right). b Quantitative analysis of regulatory T cell frequency is shown as median with interquartile range for the treatment with either CardAP-EV variant and PBS ( $n=6$; four different CardAP donors; four different PBMC donors). $c$ Concentration of released IL-1RA by CD $14^{+}$cells after 2 -days treatment with either CardAP EV variant or PBS is shown as median with interquartile range ( $n=6$, four different CardAP donors, four different PBMC donors). Friedman Test with Dunn's multiple comparison test: ${ }^{* *} p<.001,{ }^{* *} p<.01,{ }^{*} p<.05$ or Wilcoxon matched-pairs signed rank test; ${ }^{\# \#} p<.001,{ }^{\# \#} p<.01, \# p<.05$

expressing lower levels of HLA-DR, CD86 and enhanced levels of PD-L1 and CD206. Studies from other groups show similar changes of these cell's phenotype upon phagocytosis of human umbilical cord MSCs [54] or treatment with EVs from glioma stem cells [55] or human adipose tissue-derived MSCs [42, 56]. Dam et al. for example, observed the down-regulation of HLA-DR and CD86 on isolated monocytes after co-culturing with human CPCs. Interestingly, this effect was facilitated independently of any IFNy pre-treatment of CPCs [48], which is in accordance to our results. Also Lo Sicco et al. demonstrated a similar phenotype, including significantly increased CD206 and reduced CD86 levels on the surface of isolated macrophages after exposure to human adipose tissuederived MSC-EVs. Moreover, their application in a cardio-toxin induced injury mouse model enhanced regeneration of the skeletal muscle, which was attributed to the increased detection of M2-type macrophage markers [56]. While de Witte et al. inhibited the adherence of monocytes, we assume that in our study CD $14^{+}$ blood monocytes had already differentiated into macrophages as visible by their treatment-independent adherence [54]. The observed changes of surface molecules on $\mathrm{CD}_{14}^{+}$cells primed by CardAP-EVs would support a partial shift towards the anti-inflammatory M2-type macrophage. It would be further fostered by the increased release of IL-1RA of purified CD14 ${ }^{+}$ cells treated with either CardAP-EV variant, while the pro-inflammatory cytokines IL-1ß and IFN $\gamma$ were not detectable. IL-1RA antagonises IL-1 $\beta$ signalling and thereby suppresses immune responses, which is a known mechanism used by M2-type macrophages [57] or even by murine bone marrow-derived MSCs to induce M2 polarization [58]. In general, the polarization of M2-type macrophages would be beneficial for a potential CardAP-EV product, since the induced macrophages release anti-inflammatory cytokines, chemokines and growth factors [59], which may enhance myocardial repair $[60,61]$. The detected increase of the M2-type marker CD206, however, might imply either beneficial effects, like an inflammationresolving function [62], or detrimental effects by inducing fibrosis [63].

So far, the mechanisms are not yet clear how the EV treatment leads to the detected alterations on $\mathrm{CD} 14^{+}$ cells, like the down-regulation of HLA-DR. It can be speculated that tetraspanins are involved, since they are well-known players in antigen-presentation and internalization of HLA-DR [64]. But also the delivery of microRNAs by CardAP-EVs might have an effect on these cells, because specific microRNAs are playing a role in the process of macrophage polarization towards M1/ M2-type [65]. Several studies confirmed the capacity of EVs from regenerative cells to deliver RNA molecules $[29,66,67]$. It has to be investigated which microRNAs CardAP-EVs do deliver and whether they differ between unstimulated and cytokine stimulated conditions. We assume a reduced antigen-presenting feature of CD14 ${ }^{+}$ cells exposed to CardAP-EVs within triggered immune cell cultures, since we observed a down-regulation of HLA-DR and CD86. Indeed, we found that mitogen and antibody induced $\mathrm{T}$ cell proliferation was significantly reduced in EV-treated PMBC cultures respectively to controls. EV-mediated effects on $\mathrm{T}$ cell proliferation are controversially discussed, as results were obtained for diminished $[35,68]$ or unaffected $[43,69] \mathrm{T}$ cell 
proliferation by EVs from glioma stem cells or MSCs from bone marrow or umbilical cord. This might reflect the heterogeneity within study design, such as different EV isolation methods or differences in the conducted immunomodulation assays. In our study, the priming of $\mathrm{CD}_{14}{ }^{+}$myeloid cells by CardAP-EVs was essential, since immune responses were not modulated in their absence. Subsequently, no EV mediated inhibition of $\mathrm{T}$ cell proliferation was detectable when solely anti-CD3 stimulated purified $\mathrm{CD}^{+} \mathrm{T}$ cells were used in the immunomodulation experiment. In presence of $\mathrm{CD}_{1} 4^{+}$cells, as seen in the experimental setup with EV-primed $\mathrm{CD} 14^{+}$cells combined with purified $\mathrm{CD}^{+}{ }^{+} \mathrm{T}$ cells, the EV-mediated suppression of $\mathrm{T}$ cell proliferation could be restored as we initially observed in whole PMBC cultures. This discrepancy between whole PBMC and purified $\mathrm{CD}^{+} \mathrm{T}$ cell cultures was also described for murine immune cells treated with murine bone marrow-derived MSCEVs [37]. Additionally, we observed that the profile of released cytokines was not altered in cultures of purified $\mathrm{T}$ cells, while combined and EV-treated cultures of isolated $\mathrm{CD} 14^{+}$with $\mathrm{CD}^{+}$cells as well as EV-treated total PBMCs displayed reduced pro-inflammatory cytokine levels (IFN $\gamma, \mathrm{TNF} \alpha$ ). The reduction of pro-inflammatory cytokines is in line with other publications, showing less release of IFN $\gamma$, TNF $\alpha$, IL- $1 \beta$ or IL-17 even in the absence of inhibiting effects on the T cell proliferation [38, 43, 52, 69]. Furthermore, PBMC cultures displayed enriched levels of active TGF $\beta$ after treatment with both EV variants, which emphasizes the reduced inflammatory response towards the applied cues. Other cytokines that confirm this observation are indicated, such as reduced IL-17 or IL-1ß levels while solely cytokine stimulated EVs increased level of IL-10. This anti-inflammatory cytokine was accelerated in previous studies, including treatment with EVs from human bone marrow-derived MSCs or glioma stem cells as well as our own studies from CardAP cells in the in vivo models $[12,38,55]$.

The question arises: how do EV-primed $\mathrm{CD} 14^{+}$cells contribute to the reduced immune response? We speculate that beside the reduction of antigen presentation, other direct cell-cell-interactions can play a role. The engulfing of PD-1 on the surface of T cells with upregulated PD-L1 on the EV-primed CD14 ${ }^{+}$cells can lead to the inhibition of $\mathrm{T}$ cell proliferation and their apoptosis [70]. Also phosphatidylserine might be involved, as its exposure on vesicles released by polymorph nuclear cells was shown to inhibit the differentiation of monocytederived dendritic cells and thereby attenuating $\mathrm{T}$ cell proliferation [71]. Additionally, paracrine mechanisms can limit immune responses, like the detected increased release of IL-1RA, but also other cytokines, chemokines or EVs from $\mathrm{CD} 14^{+}$cells themselves influence the outcome of the immune response [72]. Also, it cannot be ruled out that EV-primed $\mathrm{CD} 14^{+}$cells may affect other immune cells than $\mathrm{T}$ cells. Likewise, we observed an inferior interaction with the $\mathrm{CD} 14^{-}$immune cell subpopulations, therefore we cannot rule out that CardAP-EVs can influence other immune cells directly, as human bone marrow-derived MSC-EVs were shown to influence B cells in purified immune cell cultures [43].

Interestingly, we observed in the MS-analysis of our CardAP-EVs that galectin-1 and several proteins from the annexin family were present. They are known to be modulators of immune responses by binding of galectin- 1 to CD69 and imitating a signal cascade which promotes regulatory $\mathrm{T}$ cell development [73]. After interaction with macrophages, annexin 1 further promotes a M2-type macrophage polarization [74, 75]. In combined cultures of purified $\mathrm{CD}_{14} 4^{+}$and $\mathrm{CD}^{+}$cells an increased frequency of regulatory $\mathrm{T}$ cells was detected. The administration of human or murine bone marrow-derived MSC-EVs has been previously shown to enhance regulatory $\mathrm{T}$ cells [38, 52, 69], which happened for EVs of embryonic stem cellderived MSCs in a monocyte-dependent mode of action [52]. The ability of CardAP-EVs to enhance the proportion of regulatory $\mathrm{T}$ cells is supported by the presented data, showing increased amounts of active TGF $\beta$ in PHA and anti-CD3 stimulated PBMC cultures and increased IL-10 levels in anti-CD3 PBMCs treated with cytokine stimulated CardAP-EVs. Although IL-10 was decreased in co-cultures of $\mathrm{CD}^{+}$cells with $\mathrm{CD} 14^{+}$cells, we found that EV-treated $\mathrm{CD} 14^{+}$cells already secreted IL-1RA before adding them to the co-cultures, which is able to induce regulatory $\mathrm{T}$ cell development [40]. Supportively, it was shown in vivo that the application of CardAP cells was also increasing the number of regulatory $\mathrm{T}$ cells [13].

Based on the discovered immunomodulatory CardAPEV effects in our study a potential clinical application would be feasible. This might include cardiac diseases like myocardial infarction, ischemic heart diseases, heart failure and atherosclerosis. Moreover, modulation of adverse immune processes could be dampened via the observed shift of $\mathrm{CD} 14^{+}$cells into a pro-regenerative phenotype and the enhanced induction of regulatory $\mathrm{T}$ cells in selected autoimmune diseases, such as diabetes or arthritis. However, further studies are needed to determine the nature of delivered active molecules, like microRNAs. Furthermore, we exclusively focused on the in-depth characterization of EVs from CardAP cells and in particular the influence of a clinical relevant inflammatory environment. A direct comparison with EVs from other immune modulatory active cells, like cardiac or noncardiac MSCs, as well as cells with any known immune modulating activity was not performed, but would be 


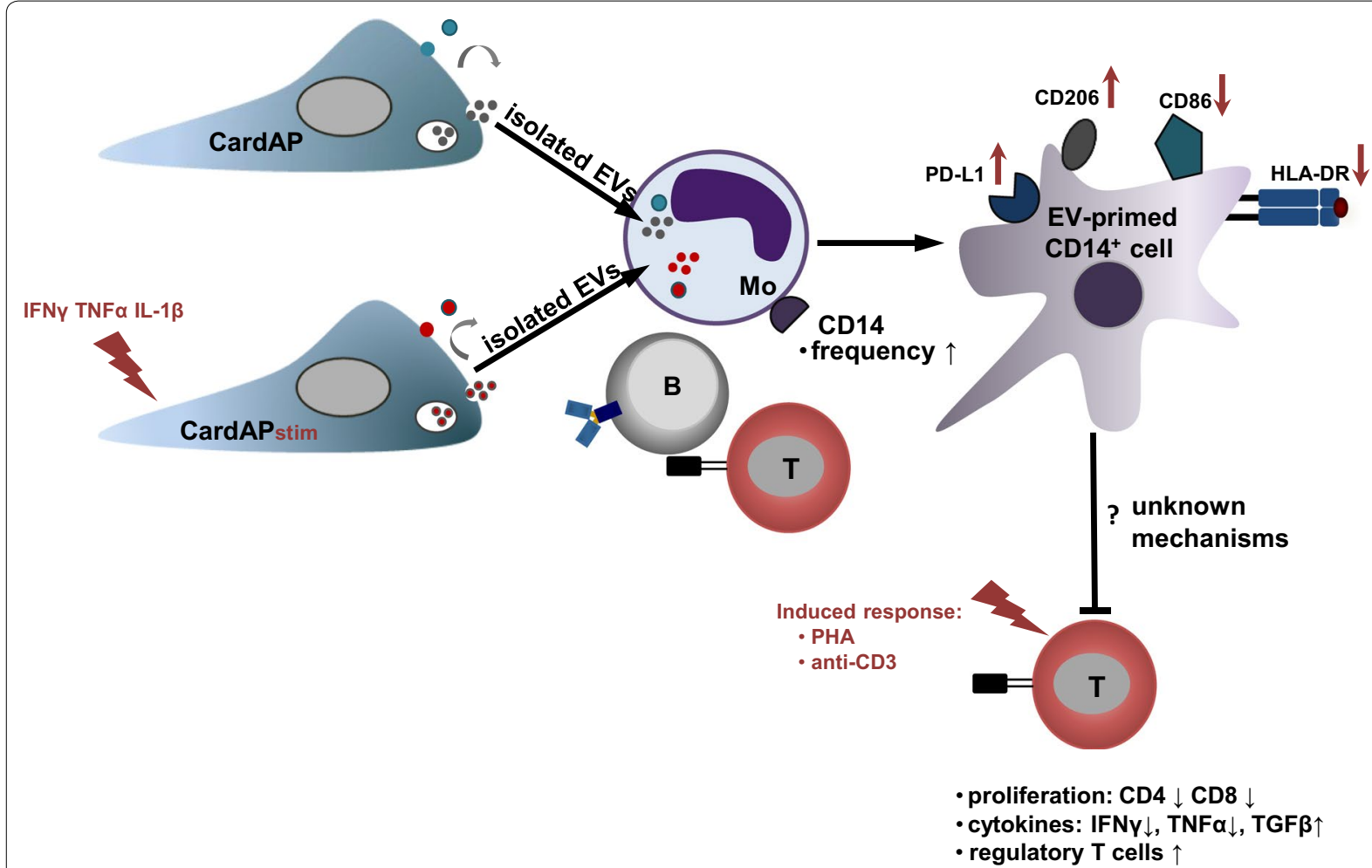

Fig. 9 Hypothesized model of the immunomodulatory effects by CardAP-EVs. CardAP cells release EVs under unstimulated or cytokine stimulation (CardAPstim). Isolated EVs interact mainly with the CD14 ${ }^{+}$monocyte subset (Mo), leading to an enhanced CD14 ${ }^{+}$frequency and a changed phenotype marked by a reduced expression of HLA-DR and CD86, but enhanced expression of CD206 and PD-L1. We showed that the development of such a CD14 ${ }^{+}$regulatory myeloid cell subset is mediating the observed attenuated $T$ cell immune responses

very interesting to be considered in future studies to distinguish between broad and specific mechanisms.

\section{Conclusions}

We found that CardAP-EVs exhibit a low immunogenicity and a capability to lower significantly pro-inflammatory immune responses in vitro. The present study provides the first evidence that the priming of $\mathrm{CD} 14^{+}$cells by cardiac-derived EVs in PBMC cultures is an essential requirement to facilitate their immune modulating features, as detected by attenuated $\mathrm{T}$ cell proliferation and proinflammatory cytokine release (summarized in Fig. 9). Overall, these findings would support an allogeneic approach of CardAP-EVs to improve cardiac regeneration.

\section{Methods}

An expanded version is available in the additional material online.

\section{Isolation of CardAP-EVs}

Isolation of EVs was performed by differential centrifugation of conditioned medium adopted from the described method by Théry et al. [27]. Shortly, cryopreserved CardAP cells, which were derived by an outgrowth culture from endomyocardial biopsies as previously described [9], were thawed and cultured in IDH medium containing $10 \%$ ultracentrifuged human serum (ucIDH), which was prepared by centrifuging IDH medium supplemented with 50\% human serum (German Red Cross, Berlin, Germany) for $24 \mathrm{~h}$ at $100,000 \times g$ (L7-55 ultracentrifuge with SW-32 Ti buckets; all from Beckman coulter, Palo Alto, CA, USA).

CardAP cells were grown in ucIDH to a confluence of about $80 \%$ and washed twice with phosphate-buffered saline (PBS; Biochrom). Afterwards, cells were either stimulated with $10 \mathrm{ng} / \mathrm{mL}$ of human tumor necrosis factor $\alpha(\mathrm{TNF} \alpha)$, human interferon- $\gamma$ (IFN $\gamma)$ and interleukin $1 \beta$ (IL-1 $\beta$; all purchased from Miltenyi Biotec, Bergisch Gladbach, Germany) or unstimulated in serumfree IDH medium. After $20 \mathrm{~h}$ under $37{ }^{\circ} \mathrm{C}$ and $5 \% \mathrm{CO}_{2}$, the conditioned medium was collected and the supernatant was stepwise centrifuged at $300 \times g$ for $10 \mathrm{~min}, 2000 \times g$ for $20 \mathrm{~min}, 12,000 \times g$ for $45 \mathrm{~min}$ and at $100,000 \times g$ for 165 min (Allegra ${ }^{\circledR}$ X-15R centrifuge and L7-55 ultracentrifuge with SW-32 Ti buckets; all from Beckman 
coulter). Then, the received EV pellet was washed with $.1 \mu \mathrm{m}$ filtered PBS by repetition of the last ultracentrifugation step. At the end, the received EV pellet was resuspended in $500 \mu \mathrm{L} .1 \mu \mathrm{m}$ filtered PBS, transferred to low-binding tubes (Sarstedt, Nümbrecht, Germany) and stored at $-80{ }^{\circ} \mathrm{C}$ till further usage. CardAP-EVs have been isolated from six different donors in passage three to seven.

\section{Size and concentration determination of CardAP-EVs}

CardAP-EVs were positive-negatively stained [27] and morphologically evaluated by transmission electron microscopy (TEM) at the EM facility of the CharitéUniversitätsmedizin Berlin. Briefly, $20 \mu \mathrm{L}$ of EVs were placed for $20 \mathrm{~min}$ on formavor-carbon coated copper EM grids (Electron Microscopy Sciences, Hatfield, PA, USA). Afterwards, following steps were performed: $20 \mathrm{~min}$ in $2 \%$ paraformaldehyde (Roth, Karlsruhe, Germany), $5 \mathrm{~min}$ in 1\% glutaralaldehyde (Sigma Aldrich, St. Louis, MO, USA), several washing steps with water and $10 \mathrm{~min}$ in freshly prepared $4 \%$ uranylacetate $2 \%$ methylcellulose (both from Sigma-Aldrich) solution. Samples were analysed by the transmission electron microscope Zeiss Leo 906 (Carl Zeiss Microscopy GmbH, Jena, Germany) run with ImageSP Viewer software version 1.2.7.11 (SYSPROG, Minsk, Belarus). For each isolation condition, at least 12 individual pictures were accessed for the diameter of EVs by ImageSP Viewer and analysed for their diameter distribution respectively. The concentration and size distribution of EVs was analysed by nanoparticle tracking analysis (NTA). Here samples were measured at ZetaView $^{\circledR}$ (Particle Metrix, Meerbusch, Germany) with the camera level 14 and according manufacture's manual. The particle concentration of EVs $/ 1 \times 10^{6}$ CardAP cells was calculated. Furthermore, the protein content was determined by Pierce ${ }^{\mathrm{TM}}$ BCA protein assay (Thermo Scientific, Rockford, IL, USA) according to the user manual. Briefly, $25 \mu \mathrm{L}$ of standards or samples were incubated together with freshly prepared working solution for $30 \mathrm{~min}$ at $60{ }^{\circ} \mathrm{C}$ in 96 -well plates $\left(\operatorname{Costar}^{\circledR}\right.$ Corning Incorporated, NY, USA). Afterwards, the absorbance was measured at $570 \mathrm{~nm}$ with a plate-reader (Mithras LB 940 and MikroWin Version 4.41 software, both from Berthold Technologies, Bad Wildbad, Germany). The amount of EV protein $/ 1 \times 10^{6}$ CardAP cells was calculated.

\section{Surface marker expression analysis of cells and EVs by flow cytometry}

The expression of surface markers on cells was investigated by staining with multicolour panels of humanspecific fluorescence labelled antibodies according to the method previously described [76] and measured by flow cytometry. Three different antibody panels were used to stain immune cells. PHA stimulated and unstimulated PBMCs were stained with following human-specific antibodies: CD8-PE (1:200) (Miltenyi Biotec), CD14APCCy7 (1:50), CD19-V450 (1:1000), CD3-PerCPCy5.5 (1:100) (BD Biosciences, San Jose, CA, USA), CD4-APC (1:100), CD56-PacificBlue ${ }^{\mathrm{TM}}$ (1:50) (BioLegend) and a viability marker in the V510 channel (1:100; LIVE/DEAD ${ }^{\circledR}$ Fixable Aqua Dead Cell Stain Kit; Invitrogen/Thermo Fisher Scientific, Eugene, OR, USA). To evaluate the phenotype of $\mathrm{CD} 14^{+}$cells in PBMC cultures, collected PBMCs were stained with human-specific antibodies: CD86-PE (1:100), PD-L1-PerCPCy5.5 (1:50), HLA-DRPECy7 (1:1000), CD206-APC (1:100), CD14-APCCy7 (1:50) and V510 viability marker. PBMCs and isolated T cells stimulated with anti-CD3 were stained with humanspecific antibodies: CD19-V450 (1:1000), CD14-APCCy7 (1:50) (BD Bioscience), CD8 PECy7 (1:50), CD4-PerCPCy5.5 (1:75), CD56-PacificBlue ${ }^{\mathrm{TM}}$ (1:50) (BioLegend) and the V510 viability marker. Afterwards the cells were washed in FACS buffer, fixed in .5\% PFA-supplemented FACS buffer and stored in the dark at $4{ }^{\circ} \mathrm{C}$ until measurement using the BD FACS-Canto II (BD Biosciences). Intracellular staining of Foxp3 was performed according the manual of Foxp3/Transcription Factor Staining Buffer Set (Invitrogen by Thermo Fisher Scientivic, Carlsbad, CA, USA). Firstly, cells were labelled on their surface as described above. Secondly, the cells were permeabilized and followed by an intracellular staining with anti-human Foxp3 AlexaFluor488 (1:400; BD Biosciences).

In contrast to cells, EVs were bound to $4 \mu \mathrm{m}$ aldehyde/ sulphate beads (Molecular Probes ${ }^{\circledR}$, Life Technologies, Eugene, OR, USA) prior to staining. Therefore, $2 \mu \mathrm{g}$ of EV-protein was incubated with $15 \mu \mathrm{L}$ of beads in PBS for $1 \mathrm{~h}$ at room temperature. After a washing step, the beads were stained with the following human-specific antibodies: CD90-APC (1:50), CD44-PECy7 (1:100), CD73-APC (1:50), CD29-PE (1:200), CD63-PE (1:1000), CD81-FITC (1:1000), CD9-FITC (1:1000), CD106-PE (1:100), PDL1-PerCPCy5.5 (1:50), CD54-APC (1:50), HLA-ABCFITC (1:100) and HLA-DR-APC (1:50; all purchased from BioLegend, San Diego, CA, USA). Finally, samples were washed, fixed in .5\% PFA-supplemented FACS buffer as described above and stored at $4{ }^{\circ} \mathrm{C}$ until measurement on a MACSQuant (Miltenyi Biotec).

All flow cytometry data were analysed with FlowJo 10.2. software (FlowJo ${ }^{\mathrm{TM}}$, LLC, RO, USA). In Additional file 1: Figure S5, the gating strategies for measuring $\mathrm{T}$ cell proliferation in PBMC and isolated T cell cultures as well as measuring surface proteins of EVs are shown. 


\section{Mass spectrometry of CardAP-EVs}

The protein composition of CardAP-EVs was analysed by liquid chromatography/electron spray ionization mass spectrometry (LC/ESI-MS) as described previously [77]. Therefore, CardAP-EVs from three different donors derived either under unstimulated or cytokine stimulation were transferred to amico filters $(10 \mathrm{kDA}$ cut off, Merck, Darmstadt, Germany) followed by an overnight digestion with Trypsin (12 $\mu$ g trypsin in $50 \mathrm{mM}$ ammonium bicarbonate; Promega, Madison; WI USA) at $37{ }^{\circ} \mathrm{C}$. Peptide samples were extracted with .1\% trifluoroacetic acid (Fluka, St. Louis, USA) and measured by UPLC (Dionex Ultimate 3000, ThermoFisher, Waltham, MA, USA) ESI-QTOF mass spectrometer (Impact II, bruker daltonics, Billerica, MA, USA). The obtained mass spectra were analysed by searching the SwissProt database (human 553474 sequences, 198069095 residues, Cambridgeshire, UK) with MASCOT software (version number 2.2, Matrix Sience, Boston, MA, USA). The following parameters were set for analysis: (i) taxonomy: Homo sapiens (Human) (20175 sequences); (ii) proteolytic enzyme: trypsin; (iii) maximum of accepted missed cleavages: 1; (iv) mass value: monoisotopic; (v) peptide mass tolerance $10 \mathrm{ppm}$; (vi) fragment mass tolerance: $.05 \mathrm{Da}$; and vii) variable modifications: oxidation. Identified proteins were considered for further analysis if scores corresponded to $p<.05$ and if at least two donors showed at least one detected peptide. Networks of protein interactions were visualized with the help of String database (version $10.5 \mathrm{http}$ ///string-db.org) as connecting line. They were considered just for high confidence interaction (.77) of active interaction sources by experiments, databases, co-expression and co-occurrences.

\section{Immune cell isolation and purification}

Peripheral blood mononuclear cells (PBMCs) were isolated from healthy blood donors by using a Biocoll gradient as described previously [76]. T cells (CD3 ${ }^{+}$cells) and monocytes $\left(\mathrm{CD} 14^{+}\right.$cells) were enriched from the PBMCs by magnetic activated cell sorting (MACS). Here, PBMCs were incubated with human-specific CD3 or CD14 MicroBeads and isolated according to the manufacturer's protocol with LS Columns (all from Miltenyi Biotec). The purity of separated cells ranged between 98.0 and $99.6 \%$ as determined by flow cytometry.

\section{Immune cell proliferation assay}

PBMCs or isolated $\mathrm{T}$ cells were analysed in a carboxyfluorescein succinimidyl ester (CFSE)-based proliferation assay. Therefore, cells were labelled with $5 \mathrm{mM}$ CFSE (Molecular Probes ${ }^{\circledR}$, Life Technologies) in PBS for $3 \mathrm{~min}$ and washed twice in complete RPMI (Biochrom) medium containing $10 \%$ ultracentrifuged human serum,
$1 \%$ penicillin/streptomycin and $1 \%$ L-glutamine $\left(\right.$ Gibco $^{\circledR}$ Life Technologies). In 96-well plates (costar ${ }^{\circledR}$, Corning Incorporated) $3 \times 10^{5}$ labelled PBMCs were seeded per well and applied either to $12.5 \mathrm{ng} / \mathrm{mL}$ of anti-CD3 antibody (OKT3; Janssen-Cilag, Neuss, Germany), .5 $\mu \mathrm{g} /$ $\mathrm{mL}$ phytohemagglutin (PHA, Sigma Aldrich, St. Louis, MO, USA) or left unstimulated. Unstimulated and antiCD3 stimulated immune cells were treated with $12 \mu \mathrm{g} /$ mL cytokine-stimulated or unstimulated EVs, while PHA stimulated PBMCs just received $6 \mu \mathrm{g} / \mathrm{mL}$ of EVs respectively. As controls, immune cells were treated with PBS in equal volume as EVs or left untreated. For the co-culture of isolated $\mathrm{T}$ cells and $\mathrm{CD} 14^{+}$cells, the $\mathrm{CD} 14^{+}$cells were $48 \mathrm{~h}$ prior to the assay treated with either CardAPEV variant, PBS or left untreated. Afterwards, the cells were co-cultured with isolated $\mathrm{T}$ cells in a 1 to 5 ratio and treated with anti-CD3 as previously described. After three or 5 days, supernatants and immune cells were collected for further analysis.

\section{Detection of cytokines in immune cell cultures}

Supernatants were analysed for IFN $\gamma$ and active TGF $\beta$ using an enzyme-linked immunosorbent assay (ELISA; ELISA MAX ${ }^{\mathrm{TM}}$ Deluxe; BioLegend) according to the manufacturer's protocol. Samples were measured at $450 \mathrm{~nm}$ and $570 \mathrm{~nm}$ on a plate reader (Mithras LB 940 and MikroWin Version 4.41 software, both from Berthold Technologies). The cytokines TNF $\alpha$, IL-1 $\beta$, IL-17a and IL-10, as well as the soluble receptor, IL-1RA, were evaluated using a multiplex bead-based assay (LEGENDplex ${ }^{\mathrm{TM}}$, BioLegend) according to the manufacturer's protocol. Multiplex samples were measured by flow cytometry at a BD FACS-Canto II (BD Biosciences) and analysed with LEGENDplex $^{\mathrm{TM}}$ version 7.1 (VigeneTech Inc, Carlisle, MA, USA).

\section{Determination of recipient cells for CardAP-EVs}

EVs were labelled with $6 \mu \mathrm{L}$ Vybrant ${ }^{\circledR}$ DiD (Invitrogen $^{\text {TM }}$, Molecular Probes, Eugene, OR, USA) in $6 \mathrm{~mL}$ PBS for $10 \mathrm{~min}$ on ice prior to the final EV isolation step. A negative control ( $\mathrm{DiD}^{-}$control) without any EVs was processed in the same manner. After the centrifugation, both samples were reconstituted in $500 \mu \mathrm{L} 0.1 \mu \mathrm{m}$ filtered PBS and stored at $-80{ }^{\circ} \mathrm{C} .5 \times 10^{5}$ unlabelled PBMCs were treated with $12 \mu \mathrm{g} \mathrm{DiD}^{+} \mathrm{EVs}$ or equal volume of $\mathrm{DiD}^{-}$control for $24 \mathrm{~h}$ at $37^{\circ} \mathrm{C}$. Afterwards, cells either were harvested for flow cytometric analysis as previously described or analysed by microscopy. Here, cells were washed with PBS, fixed with 4\% PFA in PBS and labelled with human-specific CD14 APCCy7 antibody (BD Biosciences) and 4',6-diamidino-2-phenylindole (DAPI; Molecular Probes ${ }^{\circledR}$, Life Technologies). After two washing steps, cells were examined in $20 \times$ magnification with 
the help of an AxioObserver microscope running AxioVision software (both from Carl Zeiss Microscopy $\mathrm{GmbH}$ ).

\section{Statistical analysis}

All data are shown as median with interquartile range. Statistical differences were determined either for two groups using Mann-Whitney nonparametric t-tests or Wilcoxon matched-pairs signed rank test for paired samples. More than two groups were tested by a Friedman's Test with Dunn's Post Test for paired nonparametric samples. Results were considered significant with * $\mathrm{p}<.05$, $* \mathrm{p}<.01, * * \mathrm{p}<.001$. Statistical analysis was performed using GraphPad Prism 6.0 software (GraphPad Software Inc, San Diego, CA, USA).

\section{Additional file}

Additional file 1. Additional figures and table.

\begin{abstract}
Abbreviations
CardAPs: human cardiac-derived adherent proliferating cells; CD: cluster of differentiation; CPCs: cardiac progenitor cells; CVD: cardiovascular diseases; EVs: extracellular vesicles; IFNY: interferon gamma; IL: interleukin; IL-1RA: interleukin 1 receptor antagonist; LC/ESI-MS: liquid chromatography/electron spray ionization mass spectrometry; MSCs: mesenchymal stromal cells; PBMCs: peripheral blood mononuclear cells; PBS: phosphate buffer saline; PHA: phytohemagglutin; TGFß: transforming growth factor beta; TNFa: tumour necrosis factor alpha.
\end{abstract}

\section{Acknowledgements}

The authors would like to thank the Berlin-Brandenburg Center for Regenerative Therapies (BCRT) flow cytometry facility, led by Désirée Kunkel, and Petra Schrade from the electron microscopy facility at the Charité-Universitätsmedizin Berlin for performing the TEM analysis. Many thanks to Grit Nebrich from the Tissue Typing Core facility at the Charité Universitätsmedizin for preparing and measuring the CardAP-EVs by LC/EM MS. We also would like to thank Anja Fleischmann for excellent technical support and Meaghan Stolk and Naima Souidi for editing the mansucript. We acknowledge support from the German Research Foundation (DFG) and the Open Access Publication Fund of Charité-Universitätsmedizin Berlin.

\section{Authors' contributions}

CB was responsible for the study design, performed the experiment, analysed and interpreted the data and was a major contributor in writing the manuscript. OK analysed and helped to interpret mass spectrometry data. MH, M Sittinger supplied study material and contributed together with SL to the interpretation of the experimental data. M Seifert was responsible for the project conception, study design, data interpretation and manuscript writing. All authors read and approved the final manuscript.

\section{Funding}

This work was supported by the Friede-Springer-Herz-Stiftung and in part by the Einstein Stiftung [EZ-2016-289].

\section{Ethics approval and consent to participate}

Peripheral blood mononuclear cells (PBMCs) were isolated from buffy coats (German Red Cross, Berlin, Germany) or from healthy volunteers with written informed consent using protocols approved by the ethics committee of the Charité-Universitätsmedizin Berlin (EA1/226/14, EA2/139/10). Tissues for cardiac cell isolation were obtained according to the local guidelines of the
Charité-Universitätsmedizin Berlin and the study was approved by the ethics committee of the Charité-Universitätsmedizin Berlin (EA2/140/16).

\section{Consent for publication}

Not applicable.

\section{Competing interests}

The authors declare that they have no competing interests.

\section{Availability of data and materials}

The datasets used and analysed during the current study are available from the corresponding author on reasonable request. In general, data generated or analysed during this study are included in this published article and its additional file.

\section{Author details}

${ }^{1}$ Charité-Universitätsmedizin Berlin, BCRT-Berlin, Institute Of Health Center for Regenerative Therapies, 10178 Berlin, Germany. ${ }^{2}$ Institute of Medical Immunology, Charité-Universitätsmedizin Berlin, Corporate Member of Freie Universität Berlin, Humboldt-Universität zu Berlin, and Berlin Institute of Health, Campus Virchow Klinikum (CVK), Foehrer Str. 15, 13353 Berlin, Germany. ${ }^{3}$ Tissue Engineering Laboratory, Charité-Universitätsmedizin Berlin, Corporate Member of Freie Universität Berlin, Humboldt-Universität zu Berlin, and Berlin Institute of Health, Berlin, Germany. ${ }^{4}$ Department of Internal Medicine and Cardiology, Campus Virchow Klinikum, Charité-Universitätsmedizin Berlin, Corporate Member of Freie Universität Berlin, Humboldt-Universität zu Berlin, and Berlin Institute of Health, Berlin, Germany. ${ }^{5}$ DZHK (German Center for Cardiovascular Research), Partner Site, Berlin, Germany. ${ }^{6}$ Core Unit Tissue Typing, Charité-Universitätsmedizin Berlin, Corporate Member of Freie Universität Berlin, Humboldt-Universität zu Berlin, and Berlin Institute of Health, 13353 Berlin, Germany.

Received: 11 March 2019 Accepted: 17 May 2019

Published online: 27 May 2019

\section{References}

1. World Health Organization. World Health Statistics 2018: Monitoring Health for the SDGs. Sustainable development goals. 1st ed. New York: Geneva; 2018.

2. Van Linthout S, Stamm C, Schultheiss H-P, Tschöpe C. Mesenchymal stem cells and inflammatory cardiomyopathy: cardiac homing and beyond. Cardiol Res Pract. 2011;2011:757154

3. Savvatis K, van Linthout S, Miteva K, Pappritz K, Westermann D, Schefold $J C$, et al. Mesenchymal stromal cells but not cardiac fibroblasts exert beneficial systemic immunomodulatory effects in experimental myocarditis. PLOS ONE. 2012;7(7):1-16.

4. Gerstenblith G, Johnston PV, Marbán L, Bonow RO, Marbán E, Mendizabal A, et al. Intracoronary cardiosphere-derived cells after myocardial infarction. J Am Coll Cardiol. 2013;63(2):110-22.

5. Montanari S, Dayan V, Yannarelli G, Billia F, Viswanathan S, Connelly KA, et al. Mesenchymal stromal cells improve cardiac function and left ventricular remodeling in a heart transplantation model. J Hear Lung Transplant. 2015;34(11):1481-8.

6. Makkar RR, Demaria A, Traverse JH, Marbán L, Pogoda JM, Henry TD, et al. ALLogeneic Heart STem cells to achieve myocardial regeneration (ALLSTAR) trial: rationale and design. Cell Transplant. 2016;26(2):205-14.

7. Madonna R, Van Laake LW, Botker HE, Davidson SM, De Caterina R, Engel FB, et al. ESC Working Group on Cellular Biology of the Heart: position paper for cardiovascular research: tissue engineering strategies combined with cell therapies for cardiac repair in ischaemic heart disease and heart failure. Cardiovasc Res. 2019;115(3):488-500.

8. Van Linthout S, Stamm C, Schultheiss H-P, Tschöpe C. Mesenchymal stem cells and inflammatory cardiomyopathy: cardiac homing and beyond. Cardiol Res Pract. 2011;6(2011):757154.

9. Haag M, Van Linthout S, Schröder SEA, Freymann U, Ringe J, Tschöpe $\mathrm{C}$, et al. Endomyocardial biopsy derived adherent proliferating cells-a potential cell source for cardiac tissue engineering. J Cell Biochem. 2010;109(3):564-75. 
10. Haag M, Ritterhoff J, Dimura A, Miteva K, Van Linthout S, Tschöpe C, et al. Pro-angiogenic effect of endomyocardial biopsy-derived cells for cardiac regeneration. Curr Tissue Eng. 2013;2:154-9.

11. Haag M, Stolk M, Ringe J, Van Linthout S, Tschöpe C, Sittinger M, et al. Immune attributes of cardiac-derived adherent proliferating (CAP) cells in cardiac therapy. J Tissue Eng Regen Med. 2013;7(5):362-70. https:// doi.org/10.1002/term.531.

12. Miteva K, Haag M, Peng J, Savvatis K, Becher PM, Seifert M, et al. Human cardiac-derived adherent proliferating cells reduce murine acute coxsackievirus B3-induced myocarditis. PLoS ONE. 2011;6(12):1-16.

13. Miteva K, Van Linthout S, Pappritz K, Müller I, Spillmann F, Haag M, et al. Human endomyocardial biopsy specimen-derived stromal cells modulate angiotensin II-induced cardiac remodeling. Stem Cells Transl Med. 2016;5(12):1707-18. https://doi.org/10.5966/sctm.2016-0031.

14. Wang $M, Y u$ Q, Wang L, Gu H. Distinct patterns of histone modifications at cardiac-specific gene promoters between cardiac stem cells and mesenchymal stem cells. Am J Physiol Physiol. 2013;304(1 1):C1080-90. https://doi.org/10.1152/ajpcell.00359.2012.

15. Cheng K, Ibrahim A, Hensley MT, Shen D, Sun B, Middleton R, et al. Relative roles of CD90 and c-Kit to the regenerative efficacy of cardiosphere-derived cells in humans and in a mouse model of myocardial infarction. J Am Heart Assoc. 2014;3(5):e001260. https://doi. org/10.1161/JAHA.114.001260.

16. Toma C, Pittenger MF, Cahill KS, Byrne BJ, Kessler PD, Toma C, et al. Human mesenchymal stem cells differentiate to a cardiomyocyte phenotype in the adult murine heart. Circulation. 2002;105:93-8.

17. Wang T, Xu Z, Jiang W, Ma A. Cell-to-cell contact induces mesenchymal stem cell to differentiate into cardiomyocyte and smooth muscle cell. Int J Cardiol. 2006;109(1):74-81.

18. Antonitsis P, loannidou-Papagiannaki E, Kaidoglou A, Papakonstantinou C. In vitro cardiomyogenic differentiation of adult human bone marrow mesenchymal stem cells. The role of 5-azacytidine. Interact Cardiovasc Thorac Surg. 2007;6(5):593-7.

19. Müller-Ehmsen J, Krausgrill B, Burst V, Schenk K, Neisen UC, Fries JWU, et al. Effective engraftment but poor mid-term persistence of mononuclear and mesenchymal bone marrow cells in acute and chronic rat myocardial infarction. J Mol Cell Cardiol. 2006;41(5):876-84.

20. He J, Cai Y, Luo L-M, Liu H-B. Hypoxic adipose mesenchymal stem cells derived conditioned medium protect myocardial infarct in rat. Eur Rev Med Pharmacol Sci. 2015;19:4397-406.

21. Hynes B, Kumar AHS, O'Sullivan J, Klein Buneker C, Leblond A-L, Weiss $\mathrm{S}$, et al. Potent endothelial progenitor cell-conditioned media-related anti-apoptotic, cardiotrophic, and pro-angiogenic effects post-myocardial infarction are mediated by insulin-like growth factor-1. Eur Heart J. 2013;34(10):782-9.

22. Gnecchi MO, He H, Liang OD, Melo LG, Morello F, Mu H, et al. Paracrine action accounts for marked protection of ioschemic heart by Aktmodified mesenchymal stem cells. Nat Med. 2005;11(4):367-8.

23. Kowal J, Arras G, Colombo M, Jouve M, Morath JP, Primdal-Bengtson $B$, et al. Proteomic comparison defines novel markers to characterize heterogeneous populations of extracellular vesicle subtypes. Proc Natl Acad Sci. 2016;113(8):E968-77.

24. Andreu Z, Yáñez-Mó M. Tetraspanins in extracellular vesicle formation and function. Front Immunol. 2014;5(1):1-12.

25. Kowal J, Tkach M, Théry C. Biogenesis and secretion of exosomes. Curr Opin Cell Biol. 2014;29:116-25.

26. Sluijter JPG, Van Rooij E. Exosomal microRNA Clusters Are Important for the Therapeutic Effect of Cardiac Progenitor Cells. Circ Res. 2015;116:219-21.

27. Théry C, Clayton A, Amigorena S, Raposo G. Isolation and characterization of exosomes from cell culture supernatants. In: Current protocols in cell biology. New York: Wiley; 2006. p 1-29. .

28. Barile L, Milano G, Vassalli G. Beneficial effects of exosomes secreted by cardiac-derived progenitor cells and other cell types in myocardial ischemia. Stem Cell Investig. 2017:4:1-13.

29. Gray WD, French KM, Ghosh-Choudhary S, Maxwell JT, Brown ME, Platt $\mathrm{MO}$, et al. Identification of therapeutic covariant microRNA clusters in hypoxia-treated cardiac progenitor CElls exosomes using systems biology. Circ Res. 2015;116:255-63.
30. Chen L, Wang Y, Pan Y, Zhang L, Shen C, Qin G, et al. Cardiac progenitorderived exosomes protect ischemic myocardium from acute ischemia/ reperfusion injury. Biochem Biophys Res Commun. 2013;431 (3):566-71.

31. Barile L, Lionetti V, Cervio E, Matteucci M, Gherghiceanu M, Popescu LM, et al. Extracellular vesicles fromhuman cardiac progenitor cells inhibit cardiomyocyte apoptosis and improve cardiac function aftermyocardial infarction. Cardiovasc Res. 2014;103(4):530-41.

32. Xiao J, Pan Y, Li XH, Yang XY, Feng YL, Tan HH, et al. Cardiac progenitor cell-derived exosomes prevent cardiomyocytes apoptosis through exosomal miR-21 by targeting PDCD4. Cell Death Dis. 2016;7(6):e2277.

33. de Lemos JA, Morrow DA, Blazing MA, Jarolim P, Wiviott SD, Sabatine MS, et al. Serial measurement of monocyte chemoattractant protein-1 after acute coronary syndromes: results from the A to Z trial. J Am Coll Cardiol. 2007:50(22):2117-24.

34. Harting MT, Srivastava AK, Zhaorigetu S, Bair H, Prabhakara KS, Toledano Furman $\mathrm{NE}$, et al. Inflammation-stimulated mesenchymal stromal cell-derived extracellular vesicles attenuate inflammation. Stem Cells. 2018;36(1):79-90. https://doi.org/10.1002/stem.2730.

35. Pachler K, Ketterl N, Desgeorges A, Dunai ZA, Laner-Plamberger S, Streif $D$, et al. An in vitro potency assay for monitoring the immunomodulatory potential of stromal cell-derived extracellular vesicles. Int J Mol Sci. 2017;18(7):1-11.

36. Burrello J, Monticone S, Gai C, Gomez Y, Kholia S, Camussi G. Stem cellderived extracellular vesicles and immune-modulation. Front Cell Dev Biol. 2016:4:1-10.

37. Cosenza S, Toupet K, Maumus M, Luz-Crawford P, Blanc-Brude O, Jorgensen C, et al. Mesenchymal stem cells-derived exosomes are more immunosuppressive than microparticles in inflammatory arthritis. Theranostics. 2018:8(5):1399-410.

38. Giorda E, Scapaticci M, Luciano R, Fierabracci A, Del Fattore A, Pascucci L, et al. Immunoregulatory effects of mesenchymal stem cell-derived extracellular vesicles on T lymphocytes. Cell Transplant. 2015;24(12):2615-27. https://doi.org/10.3727/096368915X687543.

39. Zhang B, Yeo RWY, Lai RC, Sim EWK, Chin KC, Lim SK. Mesenchymal stromal cell exosome-enhanced regulatory T-cell production through an antigen-presenting cell-mediated pathway. Cytotherapy. 2018;20(5):687-96.

40. Cunningham EK, Jackson MV, McAuley DF, O'Kane CM, Krasnodembskaya AD, Morrison TJ, et al. Mesenchymal stromal cells modulate macrophages in clinically relevant lung injury models by extracellular vesicle mitochondrial transfer. Am J Respir Crit Care Med. 2017;196(10):1275-86.

41. Reis M, Mavin E, Nicholson L, Green K, Dickinson AM, Wang XN. Mesenchymal stromal cell-derived extracellular vesicles attenuate dendritic cell maturation and function. Front Immunol. 2018;9(NOV):2538.

42. López-lglesias C, Bouzid R, Luk F, Hoogduijn MJ, Gonçalves F, Merino A, et al. Membrane particles generated from mesenchymal stromal cells modulate immune responses by selective targeting of pro-inflammatory monocytes. Sci Rep. 2017;7(1):12100.

43. Di Trapani M, Bassi G, Midolo M, Gatti A, Kamga PT, Cassaro A, et al. Differential and transferable modulatory effects of mesenchymal stromal cell-derived extracellular vesicles on T, B and NK cell functions. Sci Rep. 2016; 6(1):24120. http://www.nature.com/articles/srep24120.

44. Lener T, Gimona M, Aigner L, Börger V, Buzas E, Camussi G, et al. Applying extracellular vesicles based therapeutics in clinical trials_-an ISEV position paper. J Extracell Vesicles. 2015;4(1):1-31.

45. Ketterl N, Brachtl G, Schuh C, Bieback K, Schallmoser K, Reinisch A, et al. A robust potency assay highlights significant donor variation of human mesenchymal stem/progenitor cell immune modulatory capacity and extended radio-resistance. Stem Cell Res Ther. 2015;6(1):236.

46. Malliaras K, Li TS, Luthringer D, Terrovitis J, Cheng K, Chakravarty T, et al. Safety and efficacy of allogeneic cell therapy in infarcted rats transplanted with mismatched cardiosphere-derived cells. Circulation. 2012;125(1):100-12.

47. van den Akker F, Vrijsen KR, Deddens JC, Buikema JW, Mokry M, van Laake LW, et al. Suppression of T cells by mesenchymal and cardiac progenitor cells is partly mediated via extracellular vesicles. Heliyon. 2018;4(6):1-27.

48. Dam N, Hocine HR, Palacios I, DelaRosa O, Menta R, Charron D, et al. Human cardiac-derived stem/progenitor cells fine-tune monocytederived descendants activities toward cardiac repair. Front Immunol. 2017:8:1-16. https://doi.org/10.3389/fimmu.2017.01413. 
49. Zhang R, Liu Y, Yan K, Chen L, Chen XR, Li P, et al. Anti-inflammatory and immunomodulatory mechanisms of mesenchymal stem cell transplantation in experimental traumatic brain injury. J Neuroinflamm. 2013;10:871-83.

50. Xiao J, Pan Y, Li XH, Yang XY, Feng YL, Tan HH, et al. Cardiac progenitor cell-derived exosomes prevent cardiomyocytes apoptosis through exosomal miR-21 by targeting PDCD4. Cell Death Dis. 2016;7(6):1-10.

51. Bobrie A, Colombo M, Krumeich S, Raposo G, Théry C. Diverse subpopulations of vesicles secreted by different intracellular mechanisms are present in exosome preparations obtained by differential ultracentrifugation. J Extracell Vesicles. 2012;1:1.

52. Zhang B, Yin Y, Lai RC, Tan SS, Choo ABH, Lim SK. Mesenchymal stem cells secrete immunologically active exosomes. Stem Cells Dev. 2014;23(11):1233-44. https://doi.org/10.1089/scd.2013.0479.

53. Balbi C, Piccoli M, Barile L, Papait A, Armirotti A, Principi E, et al. First Characterization of human amniotic fluid stem cell extracellular vesicles as a powerful paracrine tool endowed with regenerative potential. Stem Cells Transl Med. 2017;6(5):1340-55.

54. de Witte SFH, Luk F, Sierra Parraga JM, Gargesha M, Merino A, Korevaar SS, et al. Immunomodulation By therapeutic mesenchymal stromal cells (MSC) is triggered through phagocytosis of MSC by monocytic cells. Stem Cells. 2018;36(4):602-15. https://doi.org/10.1002/stem.2779.

55. Domenis R, Cesselli D, Toffoletto B, Bourkoula E, Caponnetto F, Manini I, et al. Systemic T Cells immunosuppression of glioma stem cell-derived exosomes is mediated by monocytic myeloid-derived suppressor cells. PLOS ONE. 2017;12(1):e0169932.

56. Sicco CL, Reverberi D, Balbi C, Ulivi V, Principi E, Pascucci L, et al. Mesenchymal stem cell-derived extracellular vesicles as mediators of antiinflammatory effects: endorsement of macrophage polarization. Stem Cells Transl Med. 2017;6(3):1018-28.

57. Shapouri-Moghaddam A, Mohammadian S, Vazini H, Taghadosi M, Esmaeili SA, Mardani F, et al. Macrophage plasticity, polarization, and function in health and disease. J Cell Physiol. 2018;233:6425-40. https:// doi.org/10.1002/jcp.26429.

58. Luz-Crawford P, Djouad F, Toupet K, Bony C, Franquesa M, Hoogduijn MJ, et al. Mesenchymal stem cell-derived interleukin 1 receptor antagonist promotes macrophage polarization and inhibits B cell differentiation. Stem Cells. 2016:34(2):483-92. https://doi.org/10.1002/stem.2254.

59. Vannella KM, Wynn TA. Mechanisms of organ injury and repair by macrophages. Annu Rev Physiol. 2016;79(1):593-617. https://doi.org/10.1146/ annurev-physiol-022516-034356.

60. Courties G, Heidt T, Sebas M, Iwamoto Y, Jeon D, Truelove J, et al. In vivo silencing of the transcription factor IRF5 reprograms the macrophage phenotype and improves infarct healing. J Am Coll Cardiol. 2014;63(15):1556-66.

61. ter Horst EN, Hakimzadeh N, van der Laan AM, Krijnen PAJ, Niessen HWM, Piek JJ. Modulators of macrophage polarization influence healing of the infarcted myocardium. Int J Mol Sci. 2015;16(12):29583-91.

62. Kambara K, Ohashi W, Tomita K, Takashina M, Fujisaka S, Hayashi R, et al. In vivo depletion of CD206+M2 macrophages exaggerates lung injury in endotoxemic mice. Am J Pathol. 2015;185(1):162-71.
63. Bellón T, Martínez V, Lucendo $B$ del Peso G Castro MJ, Aroeira $\mathrm{LS}$, et al. Alternative activation of macrophages in human peritoneum: implications for peritoneal fibrosis. Nephrol Dial Transplant. 2011;26(9):2995-3005.

64. Saiz ML, Rocha-Perugini V, Sánchez-Madrid F. Tetraspanins as organizers of antigen-presenting cell function. Front Immunol. 2018;9:1074.

65. Wang $\mathrm{N}$, Liang $\mathrm{H}$, Zen K. Molecular mechanisms that influence the macrophage M1-M2 polarization balance. Front Immunol. 2014;5:614.

66. Crescitelli R, Lässer C, Szabó TG, Kittel A, Eldh M, Dianzani I, et al. Distinct RNA profiles in subpopulations of extracellular vesicles: apoptotic bodies, microvesicles and exosomes. J Extracell Vesicles. 2013;2:1.

67. Claßen L, Tykocinski LO, Wiedmann F, Birr C, Schiller P, Tucher C, et al. Extracellular vesicles mediate intercellular communication: transfer of functionally active microRNAs by microvesicles into phagocytes. Eur J Immunol. 2017;47(9):1535-49.

68. Domenis R, Cesselli D, Toffoletto B, Bourkoula E, Caponnetto F, Manini I, et al. Systemic T cells immunosuppression of glioma stem cell-derived exosomes is mediated by monocytic myeloid-derived suppressor cells. PLOS ONE. 2017;12(1):1-23.

69. Chen W, Huang Y, Han J, Yu L, Li Y, Lu Z, et al. Immunomodulatory effects of mesenchymal stromal cells-derived exosome. Immunol Res. 2016;64(4):831-40.

70. Boussiotis VA, Chatterjee P, Li L. Biochemical signaling of PD-1 on T cells and its functional implications. Cancer J. 2014;20(4):265-71.

71. Eken C, Gasser O, Zenhaeusern G, Oehri I, Hess C, Schifferli JA. Polymorphonuclear neutrophil-derived ectosomes interfere with the maturation of monocyte-derived dendritic cells. J Immunol. 2008;180(2):817-24.

72. Théry C, Ostrowski M, Segura E. Membrane vesicles as conveyors of immune responses. Nat Rev Immunol. 2009;9:581-93.

73. Cibrián D, Sánchez-Madrid F. CD69: from activation marker to metabolic gatekeeper. Eur J Immunol. 2017;47(6):946-53. https://doi.org/10.1002/ eji.201646837.

74. Sheikh M, Solito E. Annexin A1: Uncovering the many talents of an old protein. Int J Mol Sci. 2018;19(4):1045.

75. Li Y, Cai L, Wang H, Wu P, Gu W, Chen Y, et al. Pleiotropic regulation of macrophage polarization and tumorigenesis by formyl peptide receptor-2. Oncogene. 2011;30(36):3887-99.

76. Stolk M, Klatte-Schulz F, Schmock A, Minkwitz S, Wildemann B, Seifert M. New insights into tenocyte-immune cell interplay in an in vitro model of inflammation. Sci Rep. 2010;7(1): 1-14. http://www.nature.com/articles/ s41598-017-09875-x.

77. Becker M, Maring JA, Schneider M, Martin AXH, Seifert M, Klein O, et al. Towards a novel patch material for cardiac applications: tissue-specific extracellular matrix introduces essential key features to decellularized amniotic membrane. Int J Mol Sci. 2018;19(4):1032.

\section{Publisher's Note}

Springer Nature remains neutral with regard to jurisdictional claims in published maps and institutional affiliations.
Ready to submit your research? Choose BMC and benefit from:

- fast, convenient online submission

- thorough peer review by experienced researchers in your field

- rapid publication on acceptance

- support for research data, including large and complex data types

- gold Open Access which fosters wider collaboration and increased citations

- maximum visibility for your research: over 100M website views per year

At BMC, research is always in progress.

Learn more biomedcentral.com/submissions 